\title{
Interventions to Promote Fundamental Movement Skills in Childcare and Kindergarten: A Systematic Review and Meta-Analysis
}

\author{
Kristin Wick $^{1,2}$ - Claudia S. Leeger-Aschmann ${ }^{3}$ - Nico D. Monn ${ }^{3}$ - Thomas Radtke ${ }^{3}$. \\ Laura V. Ott ${ }^{3}$ - Cornelia E. Rebholz ${ }^{3} \cdot$ Sergio $\mathrm{Cruz}^{3} \cdot$ Natalie Gerber $^{3}$. \\ Einat A. Schmutz ${ }^{3}$.Jardena J. Puder ${ }^{4,5} \cdot$ Simone Munsch $^{6} \cdot$ Tanja H. Kakebeeke $^{7}$. \\ Oskar G. Jenni ${ }^{7} \cdot$ Urs Granacher $^{1} \cdot$ Susi Kriemler ${ }^{3}$
}

Published online: 6 April 2017

(c) The Author(s) 2017. This article is an open access publication

\begin{abstract}
Background Proficiency in fundamental movement skills (FMS) lays the foundation for being physically active and developing more complex motor skills. Improving these motor skills may provide enhanced opportunities for the development of a variety of perceptual, social, and cognitive skills.

Objective The objective of this systematic review and meta-analysis was to assess the effects of FMS
\end{abstract}

Kristin Wick and Claudia S. Leeger-Aschmann are the co-first authors and Urs Granacher and Susi Kriemler are the co-last authors.

Electronic supplementary material The online version of this article (doi:10.1007/s40279-017-0723-1) contains supplementary material, which is available to authorized users.

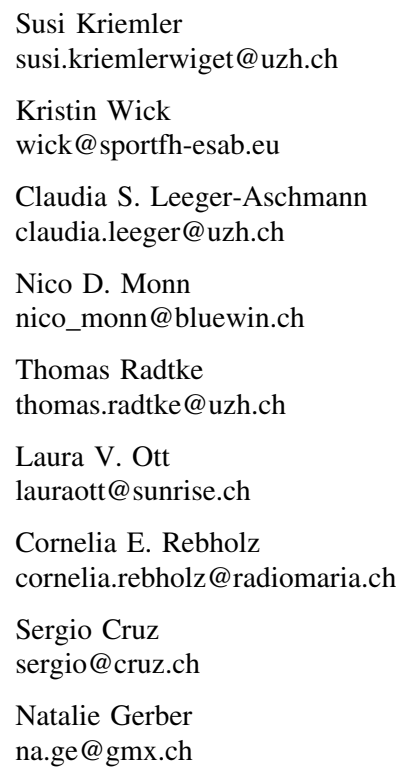

interventions on actual FMS, targeting typically developing young children.

Method Searches in seven databases (CINAHL, Embase, MEDLINE, PsycINFO, PubMed, Scopus, Web of Science) up to August 2015 were completed. Trials with children (aged 2-6 years) in childcare or kindergarten settings that applied FMS-enhancing intervention programs of at least 4 weeks and meeting the inclusion criteria were included. Standardized data extraction forms were used. Risk of bias was assessed using a standard scoring scheme (Effective Public Health Practice Project-Quality Assessment Tool for Quantitative Studies [EPHPP]). We calculated effects on overall FMS, object control and locomotor subscales (OCS and LMS) by weighted standardized mean differences $\left(\mathrm{SMD}_{\text {between }}\right)$ using random-effects models. Certainty

Einat A. Schmutz

einat.schmutz@uzh.ch

Jardena J. Puder

jardena.puder@chuv.ch

Simone Munsch

simone.munsch@unifr.ch

Tanja H. Kakebeeke

tanja.kakebeeke@kispi.uzh.ch

Oskar G. Jenni

oskar.jenni@kispi.uzh.ch

Urs Granacher

urs.granacher@uni-potsdam.de

1 Division of Training and Movement Sciences, University of Potsdam, Potsdam, Germany

2 University of Applied Science for Sport and Management Potsdam of the ESAB, Potsdam, Germany

3 Epidemiology, Biostatistics and Prevention Institute, University of Zurich, Hirschengraben 84, 8001 Zurich, Switzerland 
in training effects was evaluated using GRADE (Grading of Recommendations Assessment, Development, and Evaluation System).

Results Thirty trials (15 randomized controlled trials and 15 controlled trials) involving 6126 preschoolers (aged 3.3-5.5 years) revealed significant differences among groups in favor of the intervention group (INT) with smallto-large effects on overall FMS (SMD between 0.46 ), OCS ( $\mathrm{SMD}_{\text {between }} 1.36$ ), and LMS (SMD between 0.94$)$. Our certainty in the treatment estimates based on GRADE is very low.

Conclusions Although there is relevant effectiveness of programs to improve FMS proficiency in healthy young children, they need to be interpreted with care as they are based on low-quality evidence and immediate post-intervention effects without long-term follow-up.

$\begin{array}{ll}\text { Abbreviations } \\ \text { CI } & \text { Confidence interval } \\ \text { CON } & \text { Control group } \\ \text { CT } & \text { Controlled trial } \\ \text { EPHPP } & \begin{array}{l}\text { Effective Public Health Practice Project- } \\ \text { Quality Assessment Tool for Quantitative }\end{array} \\ & \text { Studies } \\ \text { FMS } & \text { Fundamental movement skills } \\ \text { GRADE } & \text { Grading of Recommendations Assessment, } \\ & \begin{array}{l}\text { Development, and Evaluation System } \\ \text { INT }\end{array} \text { Intervention group } \\ \text { LMS } & \text { Locomotor subscale } \\ \text { OCS } & \text { Object control subscale } \\ \text { PRISMA } & \begin{array}{l}\text { Preferred Reporting Items for Systematic } \\ \text { Reviews and Meta-Analyses }\end{array} \\ \text { RCT } & \text { Randomized controlled trial } \\ \text { SD } & \text { Standard deviation } \\ \text { SE } & \text { Standard error } \\ \text { SMD } & \text { Standardized mean difference } \\ \text { WoS } & \text { Web of Science }\end{array}$

4 Endocrinology, Diabetes and Metabolism Service, Centre Hospitalier Universitaire Vaudois (CHUV), Lausanne, Switzerland

5 Division of Pediatric Endocrinology, Diabetology and Obesity, Centre Hospitalier Universitaire Vaudois (CHUV), Lausanne, Switzerland

6 Department of Clinical Psychology and Psychotherapy, University of Fribourg, Fribourg, Switzerland

7 Child Development Center and Children's Research Center, University Children's Hospital Zurich, Zurich, Switzerland

\section{Key Points}

Proficiency in fundamental movement skills (FMS) can and should be trained and enhanced at an early age.

In this review, interventions tackling FMS improvement in typically developing young children (aged 2-6 years) show clear beneficial effects on overall FMS, locomotion, and object control skills.

As there is very little confidence in the effect estimates, and the true effect in this study is most likely different (stronger or weaker) from the effect estimate, more high-quality research with reduced bias is needed.

\section{Introduction}

Fundamental movement skills (FMS) are basic abilities and skills of a child to perform an organized series of basic movements that involve various body parts and provide the basis of achieving a high level of motor competence to develop normally, maintain health, and gain athletic excellence [1-5]. FMS is usually classified into basic locomotor skills that enable children to transfer the body in space (e.g. walking, running, jumping, sliding, hopping, and leaping), and object control skills that enable them to manipulate and project objects (i.e., throwing, catching, striking, bouncing, kicking, pulling, and pushing) [6-8]. Although locomotor and object control subscales (LMS and OCS) are reasonably well correlated $(r=0.84-0.96)$ [8], they should be differentiated, given their discrete and independent importance towards predicting health behaviors [9]. FMS are essential to the more specialized and complex skills used in play, games, and sports. Mastery of these basic motor skills that predominantly evolve during the preschool years $[8,10]$ is an essential part of pleasant participation and a lifelong interest in a physically active lifestyle [11, 12], or even of becoming an elite athlete [3].

Proficiency in FMS is considered critical to achieving and maintaining physical activity [11, 13] and physical fitness [14], preventing obesity [15-17], and developing more complex motor skills for later life [9, 10]. Yet, an increasing number of young children have insufficiently developed FMS [18-20]. Given that FMS are related to lifelong engagement in physical activity that is essential not only to maintain physical health, but likewise to support cognitive and social development during childhood [21], it is important to promote FMS during the first years of life [11]. The acquisition of FMS is not only achieved 
through natural development and maturation, but also through continuous interaction with a stimulating and supportive social and physical environment including attractive and sufficient space, a stimulating social attitude, as well as a professional instructional approach. This concept is based on a mutual interaction between the biological conditions and the environment that can be seen as a dynamic developmental system of perception and action [22]. This prepares children to engage in a wide and complex range of physical activities $[6,23]$ that induces adaptive neuro-motor development, and hence FMS $[9,10]$. Based on the conceptual models introduced by Stodden et al. [10] and Robinson et al. [9], there is likely a bidirectional interaction between actual FMS and physical activity, with the association also being mediated by perceived FMS [24] and physical fitness [14]. Although important, this mediating role is yet insufficiently studied in young children [9] and therefore not in the scope of this review.

In the past, several reviews have covered the effects of FMS intervention programs on FMS in children. However, those articles either examined healthy school-aged children $[25,26]$, children with motor disabilities or handicaps $[27,28]$, or focused on physical activity $[29,30]$, which is clearly different from FMS. The two reviews with a similar scope to ours included primarily healthy preschool children and were published 5-7 years ago [31, 32]. Although both found that interventions were effective in improving FMS, these articles were methodologically limited and therefore failed to provide solid evidence of the effectiveness of FMS intervention in preschool children. One of these systematic reviews [32] included 17 studies with an intervention duration of 6-24 weeks. Sixty percent of the included studies showed statistically significant intervention effects. However, the authors did not conduct a metaanalysis due to the low methodological quality and the large heterogeneity of the included studies. The other review [31] included 22 studies that were primarily conducted in preschoolers. Findings showed that FMS interventions of 6-35 weeks' duration produced effect sizes in the range of $0.39-0.45$ for overall FMS, OCS, or LMS. However, these authors did not perform any form of quality rating of the included studies. Further, uncontrolled studies were assessed and the meta-analysis was computed based on pre-post values of the intervention groups only.

Due to this gap in the literature, the objective of this systematic review and meta-analysis was to describe and evaluate long-term effects ( $\geq 4$ weeks) of childcare- and kindergarten-based intervention programs aiming to improve FMS in typically developing children during early childhood (ages 2-6 years). We used the Grading of Recommendations Assessment, Development, and Evaluation System (GRADE) to define certainty in effect estimates for the main outcomes. We further performed subgroup analyses to tease out whether quality, duration of the studies, or the type of teacher (e.g., childcare or kindergarten staff) influenced results. Finally, we performed exploratory analyses to identify interventions that were more effective than others by assessing differences in effect sizes according to type of FMS test used, target groups (e.g., gender), the setting (e.g., childcare versus kindergarten), or intervention characteristics (e.g., duration of the intervention).

\section{Methods}

We conducted and reported this systematic review in accordance with the Preferred Reporting Items for Systematic Reviews and Meta-Analyses (PRISMA) statement [33].

\subsection{Literature Search}

A librarian experienced in running systematic literature searches carried out a tailored literature search of papers on interventions to promote FMS using CINAHL, Embase, MEDLINE, PsycINFO, PubMed, Scopus and Web of Science from the year of the inception of each database through August 2015 (Electronic Supplementary Material [ESM] Table S1). Based on the PICOS approach [34], our search strategy focused on Population (e.g., children, preschoolers), Intervention (e.g., any type of intervention aiming at increasing FMS and reporting duration, frequency, and dose), Comparator (control group [CON] with usual childcare or kindergarten), Outcome (e.g., motor skills, running, hopping, balance skills), and Study design (e.g., controlled trial [CT], randomized controlled trial [RCT]). A repeated and broadened search approach was conducted after we retrieved a different set of eligible papers in our first searches with strategies that were too focused (e.g., preschoolers versus children, different exclusion criteria based on disease as motor handicaps or chronic disease rather than developmental delay), or too narrow (e.g., search options for the study design such as controlled study versus controlled trial or controlled intervention). Reference lists of included studies and published reviews were screened for additional potentially relevant articles.

\subsection{Eligibility Criteria}

Eligible studies were either clustered or unclustered CTs or RCTs that enrolled preschool children aged 2-6 years without major health problems or motor handicaps/disability, and assigned them to an intervention (INT) or a 
control $(\mathrm{CON})$ arm with the specified aim of improving FMS. The intervention needed to take place in a common institutional setting where children of this age range spend their days (e.g., childcare, nursery, preschool, or kindergarten settings), irrespective of whether they belonged to the school or preschool system, with the aim of improving FMS proficiency. The duration of the intervention had to be at least 4 weeks as we were not interested in short-term effects. Further, the trial had to report a standardized motor skill outcome measure (preferably baseline and post-test or pre-post delta values - means, standard deviation [SD], and standard error [SE]) in both arms (INT and CON). We excluded studies not written in English or German, where only the abstract was available, and also trials that enrolled fewer than ten children because of the limited information that we would gain from such small sized studies.

\subsection{Study Selection and Data Extraction}

Teams of reviewers (CL, KW, LO, NM, SC, SK) worked independently and checked in pairs the eligibility status of identified citations by screening titles, abstracts, and then the full paper. In case of any disagreement, consensus was reached through discussions and also by including a third person. The reviewers used a pretested standardized form to extract information from each eligible study including participants and cluster demographics, intervention details, study methodology, and outcome data. We collected primary outcome data that comprised any measured single motor skill task, composite overall (total FMS), or subscale scores (OCS, LMS) of motor skills. Studies used a wide range of methods to assess FMS (ESM Table S2) and reported a variety of different outcome measures. Other outcome measures (i.e., physical activity and body composition) are not discussed here but are described in Table 1.

\subsection{Risk of Bias Assessment}

The reviewers assessed the risk of bias of each eligible study using a slightly adapted version of the established 'Effective Public Health Practice Project Quality Assessment Tool for Quantitative Studies' (EPHPP) that has been proven valid in assessing Public Health interventions [35] (ESM Table S3). This quality assessment tool rates study procedures as 'strong', 'moderate', or 'weak' using eight scales (selection bias, study design, confounders, blinding, data collection methods, withdrawal/dropouts, intervention integrity, and analyses). The same procedure was always applied. That is, two reviewers from a group of four (CL, LO, NM, SK) independently scored the items for each study as 'strong', 'moderate', or 'weak'. In cases of disagreement, consensus was reached by discussion or third party arbitration. We provided an overall 'strong' or 'high quality' score if no 'weak' item score existed and at least four of the eight items were 'strong'. An overall 'moderate quality' score was provided with only one 'weak' item score and otherwise only 'strong' and 'moderate' item scores. The remaining studies were overall rated 'weak' or 'low quality'. The reviewers were not blinded to names of authors, institutions, journal, or the outcomes of the trials.

\subsection{Missing Data}

We contacted the authors of fourteen studies [36-49] to obtain missing information about the FMS assessments (means of standard or raw scores of single FMS items, OSC, LMS, total scores, SD, and number of participants who took part in INT and CON) to be able to conduct our meta-analysis. Of those, six authors answered $[36,38,40,43,44,49]$ and provided detailed information on the requested data. One author answered but could not help [39], and seven authors [37, 41, 42, 45-48] did not respond to our repeated requests. Of those, three studies $[41,45,46]$ provided total FMS scores in the original article that could be included in some, but not all metaanalytical calculations. The other four studies $[37,42,47,48]$ did not provide any missing data (mean and SD for single item, subscale, or total FMS scores) and therefore results for meta-analyses were not available. However, these studies reported sufficient descriptive and analytical results to be included in this review.

\subsection{Meta-Analyses}

Data were extracted for meta-analyses (KW) and checked for accuracy (CL). Studies that provided the number of participants, measures of baseline and post-test values (means and SD or SE) [50] for total FMS proficiency (total FMS score), subscales or single motor skill items were included. Post-intervention values were taken for metaanalyses. We chose the INT that focused on interventions taking place in the childcare or kindergarten setting if more than one INT was included [37, 51, 52]. Outcome data of total FMS proficiency and subscales were pooled after conversion to the most familiar and most used instrument (TGMD-2 [Test of Gross Motor Development-2nd edition]) to enhance interpretability of meta-analyses results [53]. Because of scarce subgroup data (e.g., for gender [49, 54], motivational climates [55]), these groups were combined for the meta-analysis of total FMS scores [56].

To verify the effectiveness of FMS intervention programs in childcare and kindergarten settings, we computed between-group standardized mean differences as $\mathrm{SMD}_{\text {between }}=$ (mean post-test value in INT group - mean post-test value in $\mathrm{CON}$ group)/pooled variance to report the 


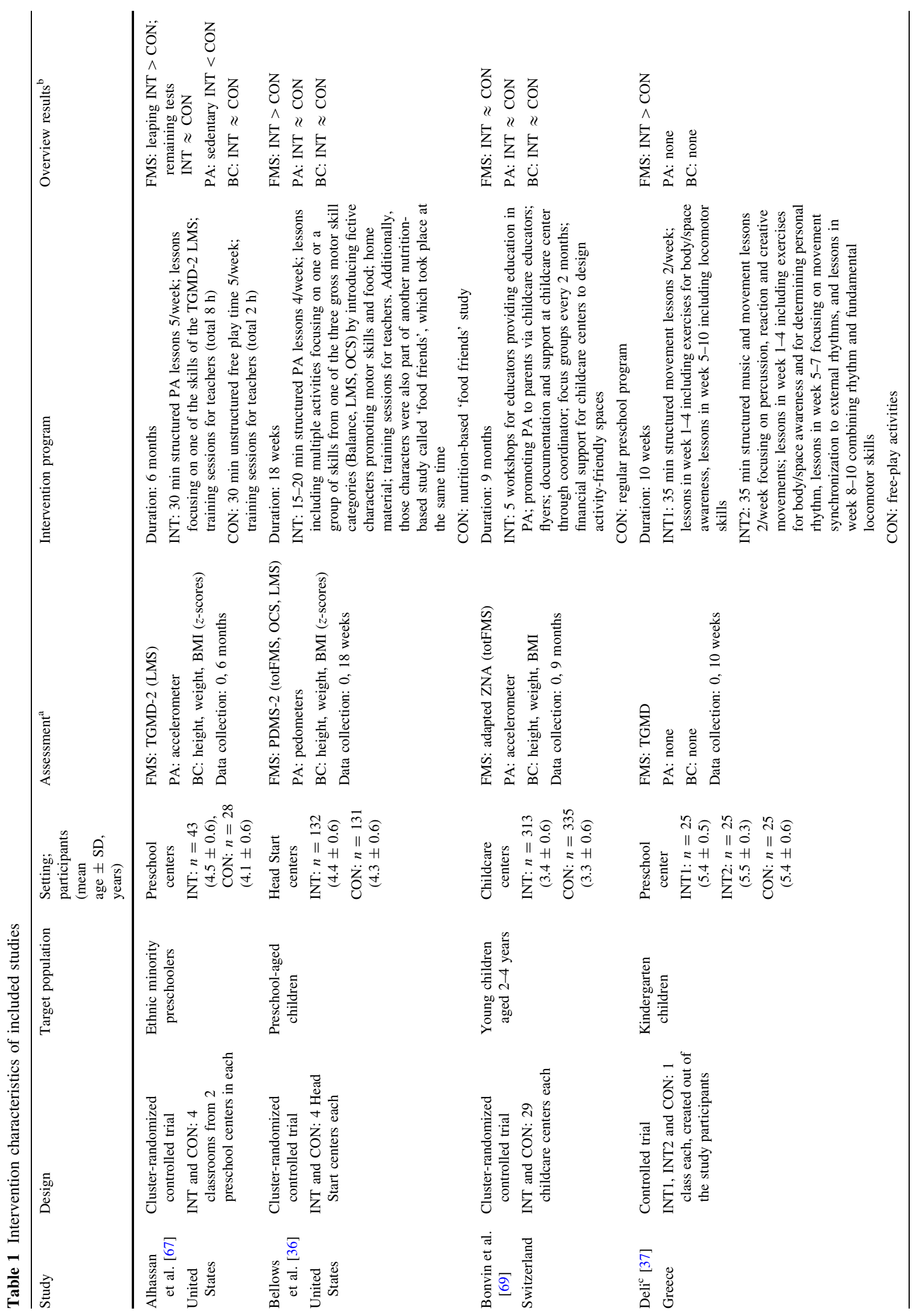




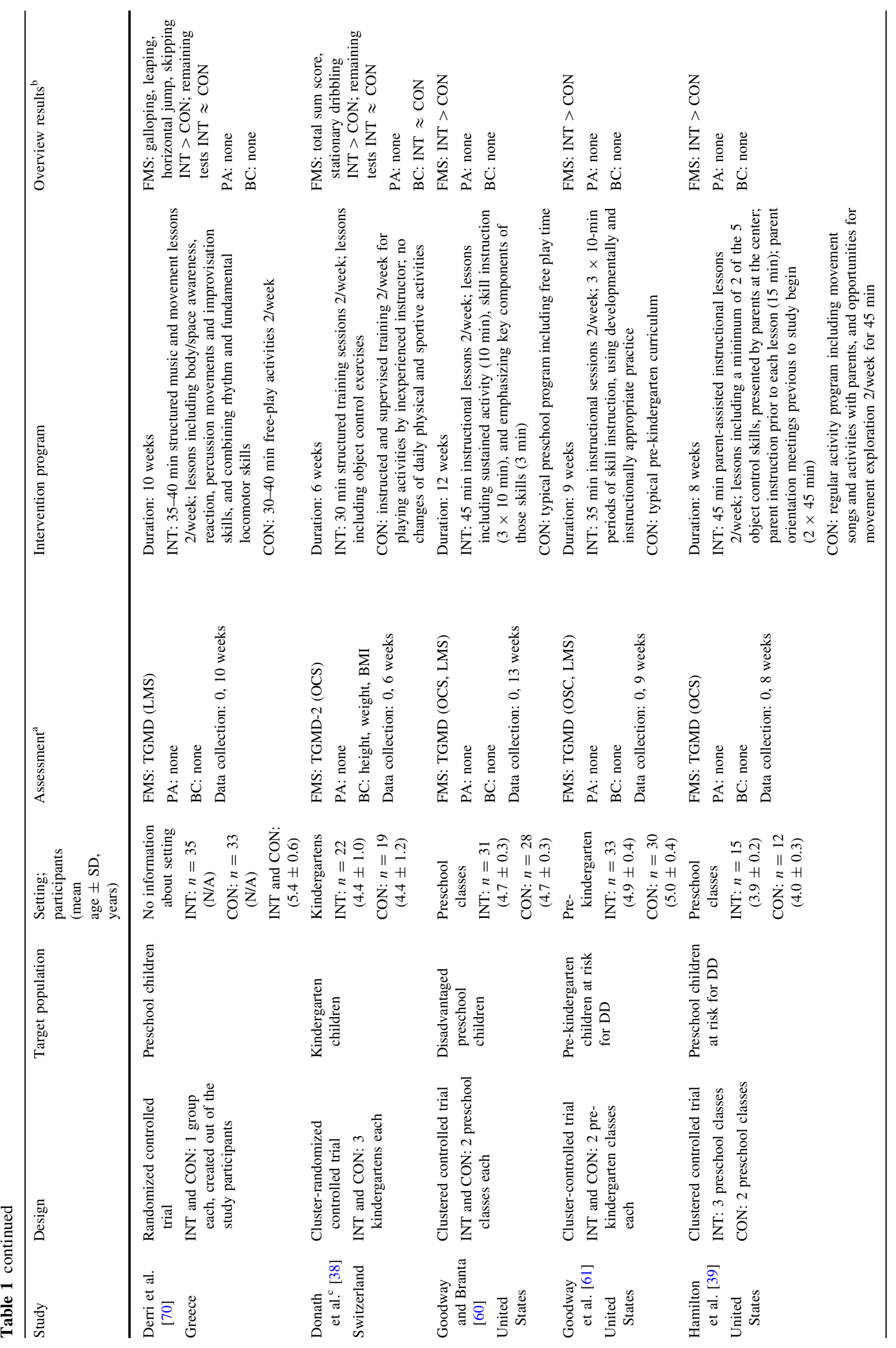




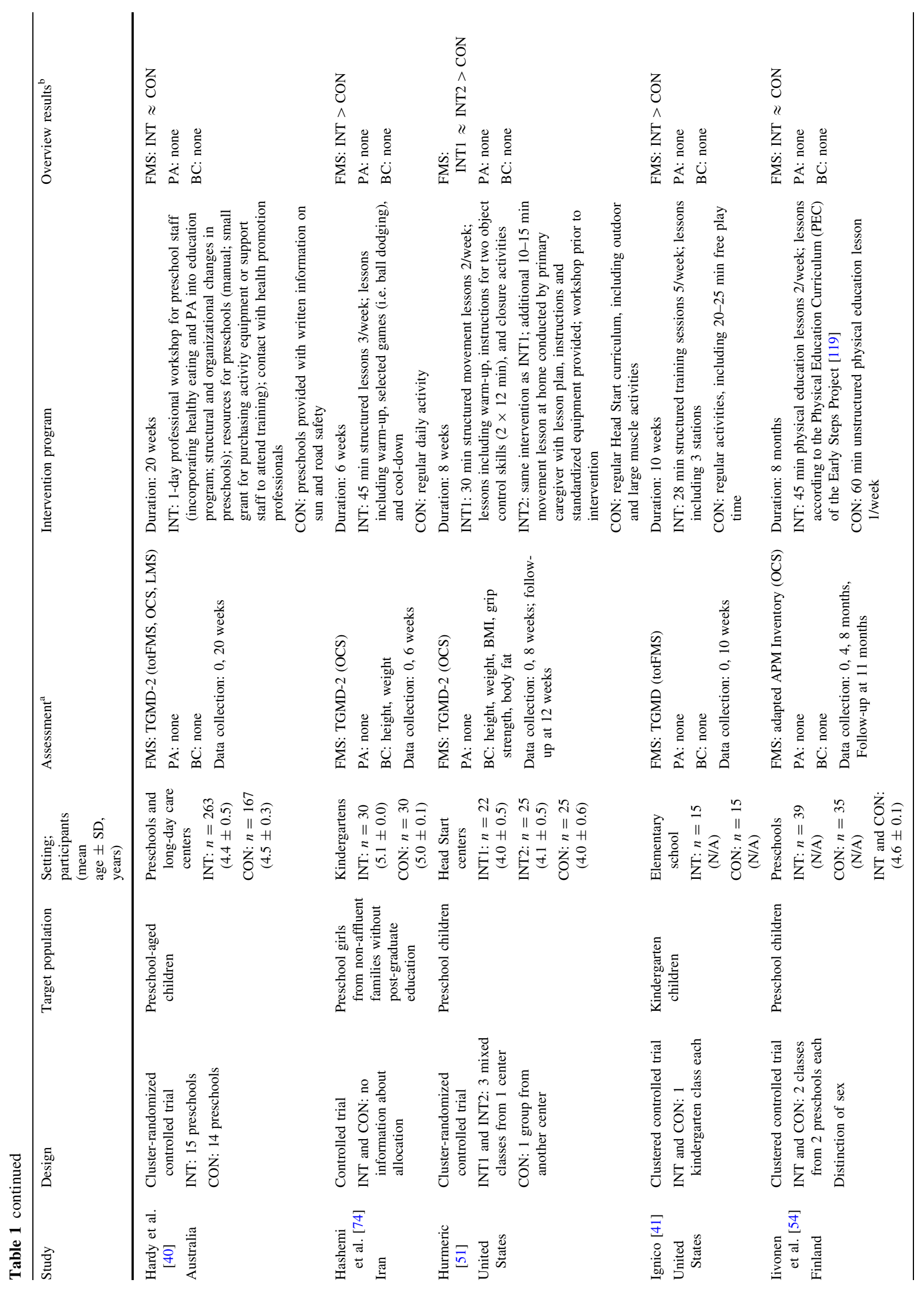




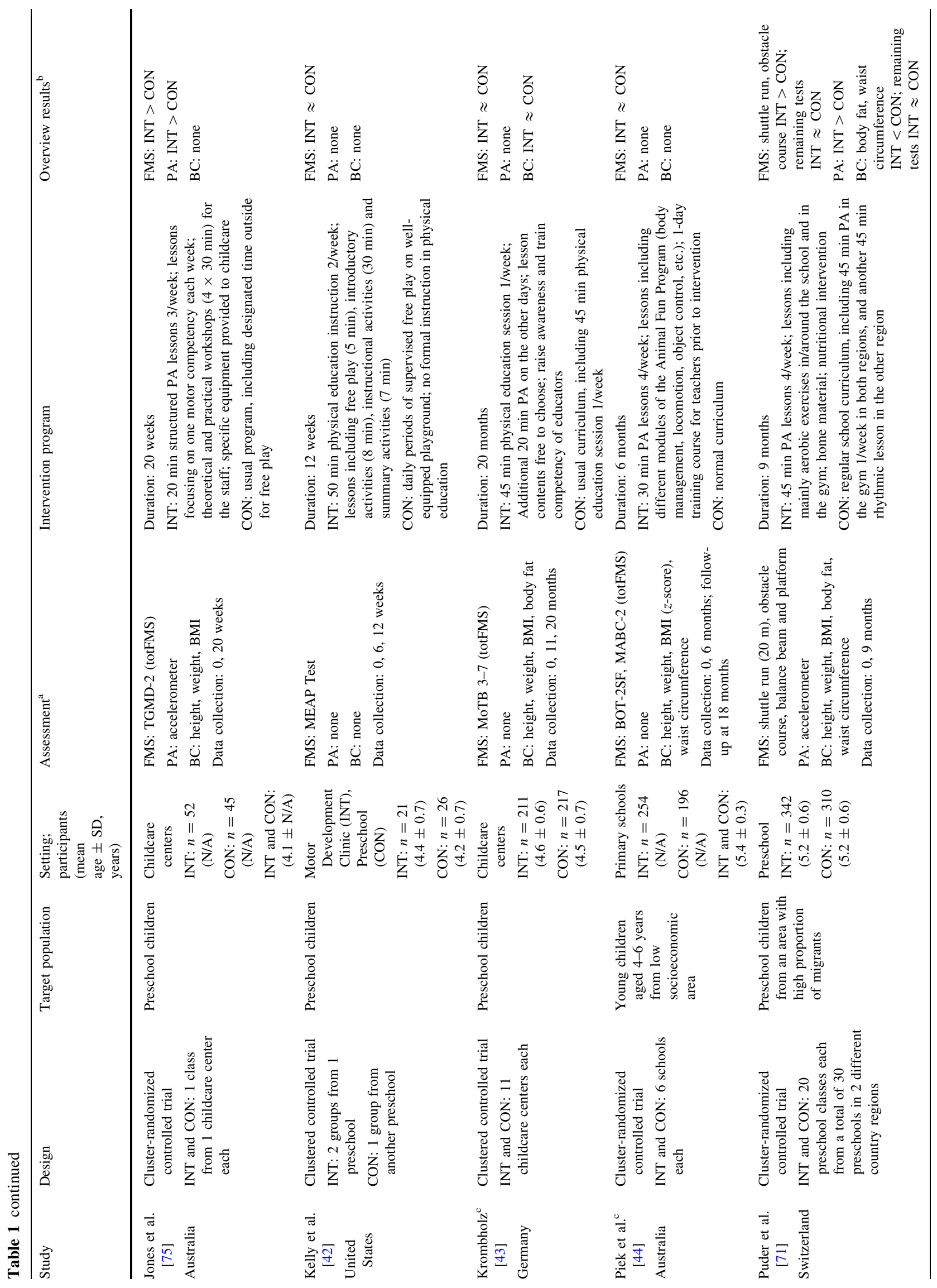









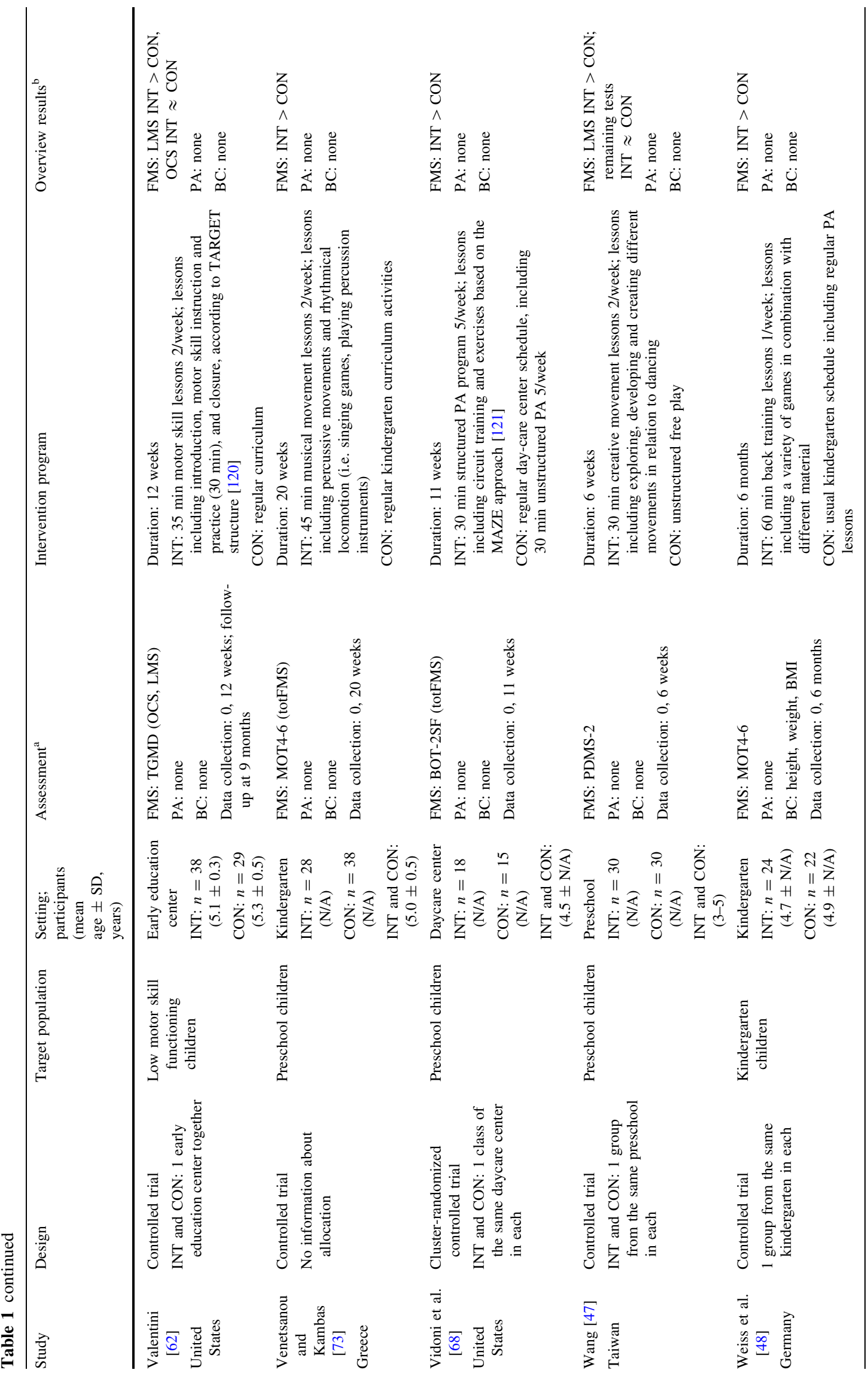




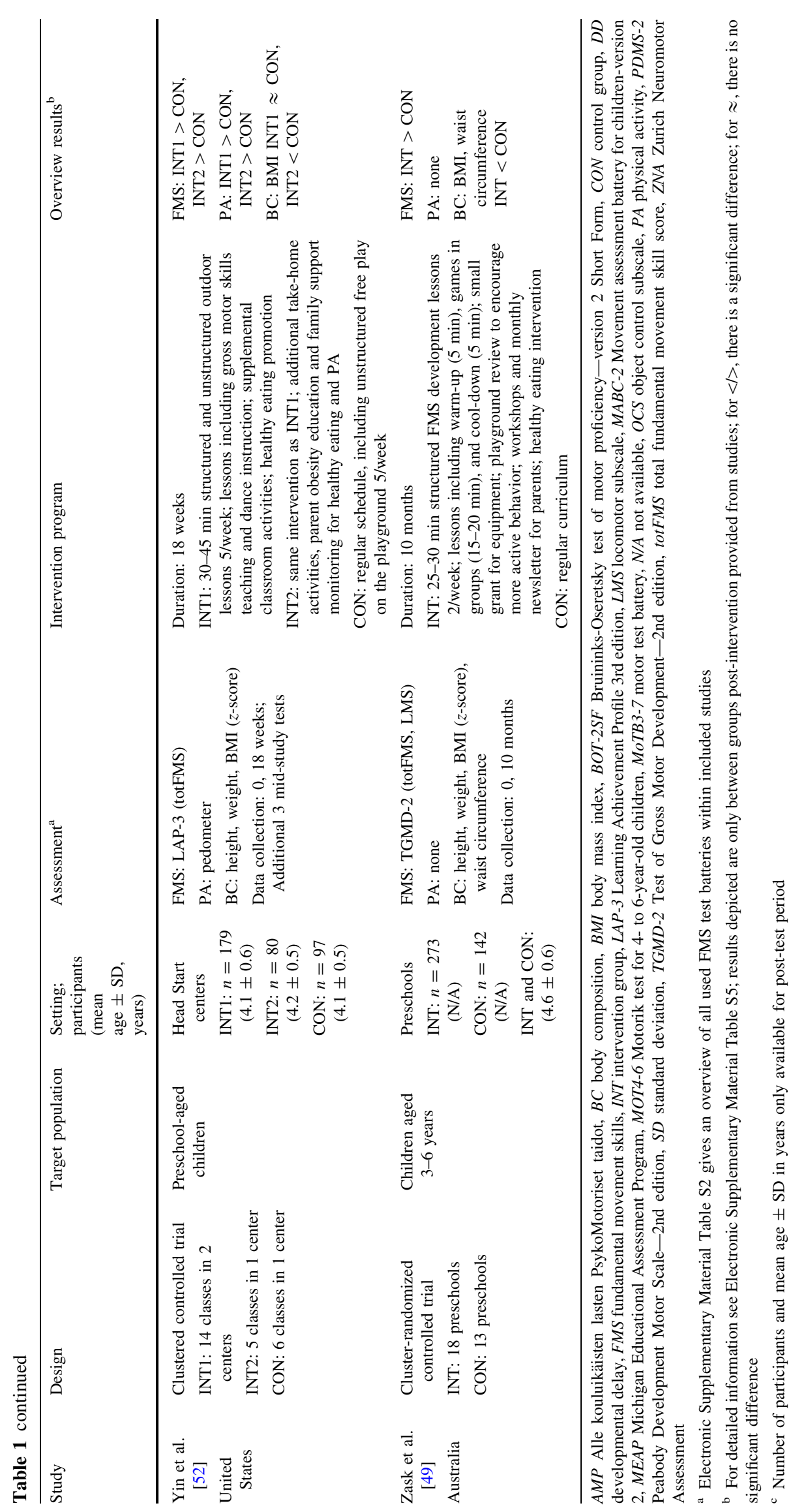


average treatment effect [50]. We combined $\mathrm{SMD}_{\text {between }}$ according to random-effect analyses to obtain an overall SMD for included studies that were further weighted for magnitude of the respective SE. SMD between were adjusted for the respective sample size (Hedges' adjusted $g$ ) [50] and expressed based on Cohen's (1988) categorizing values for $\mathrm{SMD}_{\text {within }} / \mathrm{SMD}_{\text {between of }}<0.5$ as small, $0.5-0.79$ as medium, and $\geq 0.80$ as large effects [57]. Studies that provided insufficient data to be included in meta-analyses, but fulfilled our eligibility criteria, were kept in the review [37, 42, 47, 48].

\subsection{Investigation of Heterogeneity, Subgroup and Exploratory Analyses}

Heterogeneity between studies was assessed using $I^{2}$ statistics. To explain expected heterogeneity among study results, we defined a set of two a priori hypotheses on which sensitivity analyses of subgroups were performed. First, we hypothesized that, based on social-cognitive theory [58] and the stages of behavioral change [59], an intervention of 6-8 months is the minimum amount of time needed for a sustainable change in behavior, not so much by the children themselves, but by the childcare and kindergarten professionals and the parents who direct the behavior of children at this young age. Second, we hypothesized that the results of trials would be influenced by their methodological quality. Only for this purpose, we compared 'high quality' trials based on our quality rating with 'moderate' and 'low quality' studies, respectively (ESM Table S4), using all studies that reported total FMS, OCS, or LMS scores. For three studies that reported both OCS and LMS scores but no total FMS score [60-62], the subscale scores were combined [63] to calculate the total FMS score; the variance was then determined by using a correlation between OCS and LMS of 1.0 as a conservative approach [8]. For both subgroup analyses (e.g., methodological quality, duration of the intervention) we calculated weighted mean $\mathrm{SMD}_{\text {between }}$ for the subgroups to test our hypotheses using Review Manager 5.3 (Copenhagen: The Nordic Cochrane Center, The Cochrane Collaboration, 2014). Due to the heterogeneity of FMS assessment tools used in studies, we defined a further posteriori hypothesis that test results would not vary according to the test battery used. As the majority of studies used one specific test (TGMD or TGMD-2), we compared those studies that used either version of this test battery versus those that used another test.

Further exploratory analyses were done to identify interventions that were more effective than others. These included the evaluation of differences in effect sizes according to target groups (e.g., focusing on risk populations for developmental delays rather than taking a population approach, differences in gender), the setting (e.g., kindergarten or childcare) or intervention characteristics (e.g., the use of a theoretical framework on which the intervention was built on, the integration of expert teachers versus the usual childcare or kindergarten teacher, parental involvement).

\subsection{Certainty in Treatment Estimates}

We used the GRADE approach to categorize certainty in effect estimates for all reported outcomes as high, moderate, low, or very low [64]. Based on this approach, RCTs start as high certainty but can be rated down because of risk of bias, inconsistency, indirectness, imprecision, and publication bias. CTs start as low certainty, but can be upgraded based on large magnitude effects, dose-response results or confounders that likely minimized the effect [65]. The results are presented in GRADE evidence profiles [66] using GRADEproGDT (http://www.guidelinedevelopment. org/).

\section{Results}

\subsection{Study Characteristics}

Overall, we identified 17,566 unique records, of which we assessed 41 articles for eligibility (Fig. 1). After reviewing the full texts, 30 articles were eligible including 6126 children with an age range of 3.3-5.5 years. All included trials are shown in Table 1. Twelve of the 30 studies were carried out in the US $[36,39,41,42,51,52,55,60-62,67$, 68], 12 in European countries [37, 38, 43, 45, 46, 48, 54, 69-73], and the remainder elsewhere (Iran [74], Australia [40, 44, 49, 75], and Taiwan [47]).

There were 15 RCTs [36, 38, 40, 44, 45, 49, 51, 55, 67-72, 75], including 14 cluster RCTs [36, 38, 40, 44, 45, $49,51,55,67-69,71,72,75]$, and 15 CTs $[37,39,41-43$, 46-48, 52, 54, 60-62, 73, 74] including eight cluster CT studies [39, 41-43, 52, 54, 60, 61].

The duration of the interventions ranged from 6 weeks to 20 months. Ten studies [43-45, 48, 49, 54, 67, 69, 71, $72]$ lasted $\geq 6$ months and seven studies [44, 45, 51, 54, 55, $62,72]$ had a follow-up of 9 weeks to 18 months after the end of the intervention period.

The frequency of FMS intervention sessions given per week varied between once per week to daily. Five studies [41, 52, 67, 68, 72] offered an FMS intervention every day, 22 studies [36-39, 42-47, 49, 51, 54, 55, 60-62, 70, 71, 73-75] two to four times per week, one study [48] once a week and two studies [40, 69] did not specify the frequency. Fifteen studies [36, 38, 41, 43-45, 47, 49, 51, 55, $61,67,68,72,75]$ documented single intervention sessions 


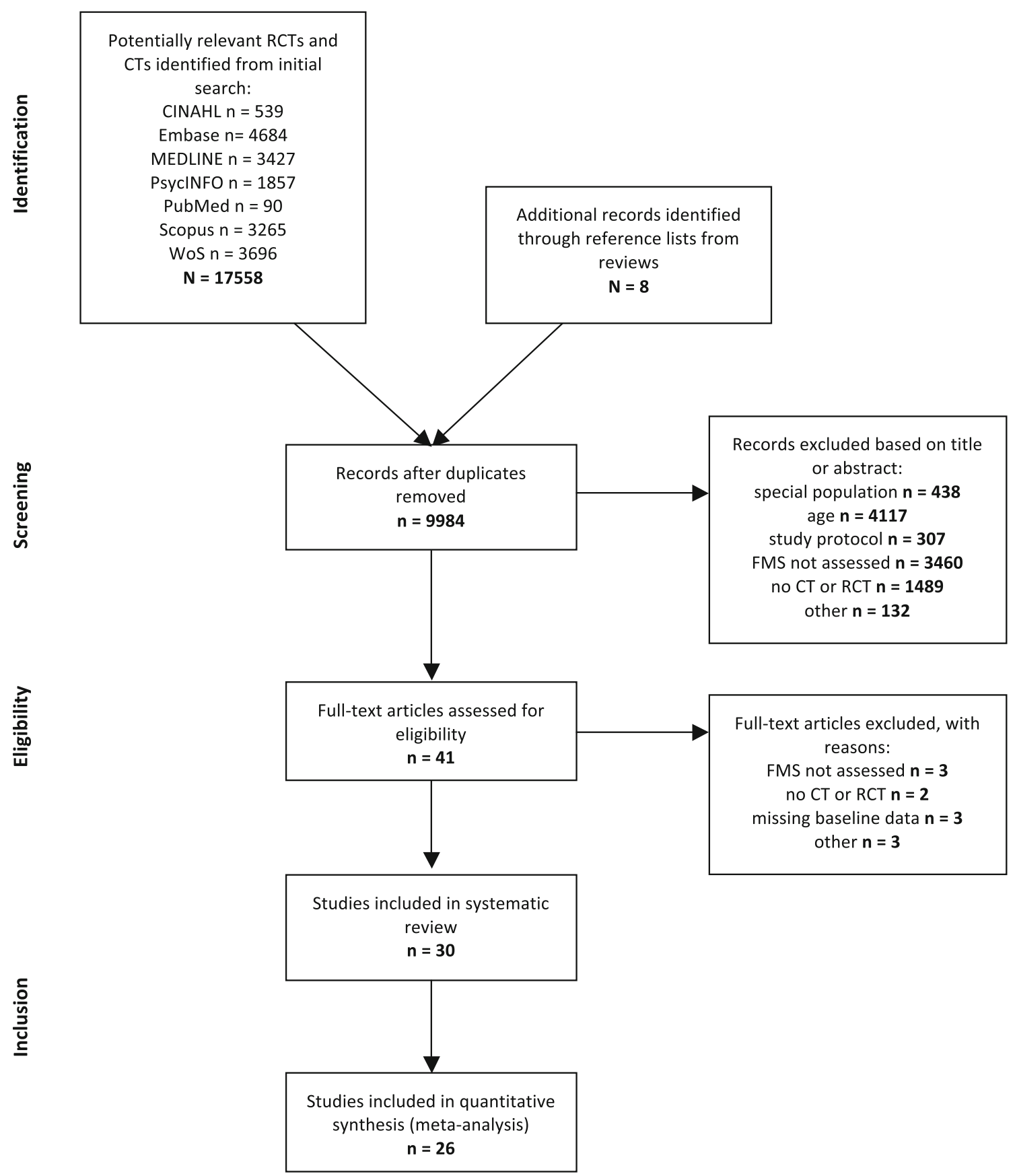

Fig. 1 Study flow chart [33]. CT controlled trial, FMS fundamental movement skills, $R C T$ randomized controlled trial, WoS Web of Science

lasting between 15 and 30 min, and 13 studies [37, 39, 42, $46,48,52,54,60,62,70,71,73,74]$ between 30 to 65 min. Two studies [40, 69] did not provide any information for duration of a single session. All interventions were carried out in childcare or kindergarten settings (i.e., nursery center, early educational center, Head Start center). All interventions included either structured FMS sessions with additional unstructured time for physical activity in five trials $[40,42,49,52,75]$ or only unstructured physical activity time but specifically devoted to improve FMS in two studies $[43,69]$. In the structured FMS sessions, the intervention protocols consisted of an overall or specific training of FMS, including object control, locomotor and balance skill exercises, but also coordinative skills, rhythm with percussions and/or music, body awareness and perception, as well as games and creative movements, and improvisation skills. Unstructured physical activity time comprised defined free outdoor playtime and/or additional playground material to encourage physically active behavior and the development of FMS. Eight studies 
$[36,39,45,49,51,69,71,72]$ also focused on parental work (homework cards and physical activity home assignments for children with promotion of physical activity and FMS to parents) and nine studies set a focus on training sessions (workshops) for staff, nurses, and educators $[36,40,43-45,49,67,69,75]$. Four studies $[36,48,52,71]$ also taught the importance of healthy eating and nutrition to the children. To assess FMS (for a precise description of all tests see ESM Table S2), 16 studies [37-41, 46, 49, 51, 55, 60-62, 67, 70, 74, 75] used the TGMD—-first or second edition, two studies [44, 68] used the BOT-2SF (Bruininks-Oseretsky Test of motor proficiency-Version 2 Short Form), two [48, 73] the MOT4-6 (Motorik Test for 4- to 6-year-old children), two [36, 47] the PDMS-2 (Peabody Development Motor Scale-2nd edition), and another eight studies [42, 43, 45, $52,54,69,71,72]$ used single items or other FMS test batteries.

\subsection{Risk of Bias}

Overall, eight out of 30 studies (27\%) [38, 40, 45, 51, 69, $71,72,75]$ were rated to be of high methodological quality (see ESM Table S4). A total of eleven studies $[36,40,43-45,49,52,55,69,71,72]$ had $>100$ participants (of those, five studies [40, 45, 69, 71, 72] were of high quality). Just six studies applied intention-to-treat analyses $[41,46,69,71,72,75]$ but most studies measured the study groups at similar times. Insufficient information was provided to score the adequacy of the randomization procedure in nine studies [36, 38, 44, 49, 51, 67-70] (30\%), and five studies $[37,38,42,47,48]$ lacked information on allocation concealment or blinding of assessors at outcome assessment. Most studies reported detailed information regarding the intervention protocol for duration of training and training content (Table 1). However, the curriculum of the CON was not specified beyond usual care in 19 of the 30 studies.

\subsection{Effects of Interventions to Improve Fundamental Movement Skills}

Findings from 26 out of 30 studies [36, 38-41, 43-46, 49, $51,52,54,55,60-62,67-75]$ were aggregated and included in different meta-analytical calculations (ESM Table S5). For four studies [37, 42, 47, 48], results for meta-analytical calculations were not available. Results of those four studies lasting 6 weeks to 6 months included two studies [37, 47] that reported statistically significant differences for the LMS at post-intervention in favor of the INT, one study [48] found statistically significant differences for overall motor proficiency in favor of the INT, and one study [42] found no significant differences in FMS among groups.
Forest plots and summary results of the meta-analyses for total FMS, OCS, and LMS are described in Fig. 2 and Table 2. Thirteen $[36,40,41,43-45,49,52,68,69,72$, $73,75]$ out of 26 studies which measured overall motor proficiency (total FMS score) showed small effects of the intervention programs on the INT compared with CON (weighted mean $\mathrm{SMD}_{\text {between }}=0.46,95 \%$ CI $0.28-0.65$; $I^{2}=83 \%$, Fig. 2a). The subscale-specific analyses revealed large effects of intervention programs on the OCS in $11[36,38-40,51,54,55,60-62,74]$ out of 26 studies (weighted mean $\mathrm{SMD}_{\text {between }}=1.36,95 \%$ CI $0.80-1.91$; $I^{2}=94 \%$, Fig. $2 \mathrm{~b}$ ) and also large effects in nine studies $[36,40,46,49,60-62,67,70]$ on the LMS (weighted mean $\mathrm{SMD}_{\text {between }}=0.94, \quad 95 \%$ CI $0.59-1.30 ; \quad I^{2}=88 \%$, Fig. 2c). Based on GRADE, there was very low certainty of evidence (Table 2) for effect sizes of the total FMS score and both subscale scores including, but not limited to, a high chance of a publication bias (ESM Fig. S1).

ESM Figs. S2-S4 illustrate forest plots of the intervention effects for single motor skill items integrated in the TGMD-2 scores, and other skills like the standing long jump and balance. Intervention effects were statistically significant in favor of INT for all single items, with effect sizes ranging from low to moderate (0.19-0.83). There was only a small number (i.e., 3-7) of studies in each meta-analysis and a high heterogeneity with $I^{2}$ ranging from 73 to $90 \%$, except for the standing long jump that showed an $I^{2}=0 \%$. There was no clear picture regarding characteristics of the interventions (frequency, duration), target population (disadvantaged children, age), or setting (childcare, kindergarten) that explained why the effectiveness in total FMS and subscales varied considerably.

\subsection{Subgroup and Exploratory Analyses}

\subsubsection{Subgroup Analyses}

Figure 3a displays the overall dose-response relationship according to the duration of the interventions. The 17 trials $[36,38-41,46,51,52,55,60-62,68,70,73-75]$ with a shorter duration (4 weeks to 5 months) showed significantly higher effect sizes on overall FMS compared with those eight studies [43-45, 49, 54, 67, 69, 72] with longer duration ( $\geq 6$ months) (weighted mean $\mathrm{SMD}_{\text {between }}=1.43$, 95\% CI 0.49-2.38). Four studies [37, 42, 47, 48] did not report their results and, for one study [71], data were available only for single items. Figure $3 b$ presents the intervention effects for 25 trials [36, 38-41, 43-46, 49, $51,52,54,55,60-62,67-70,72-75]$ according to methodological quality. Eight studies [36, 43, 49, 52, 55, $60,61,67]$ with 'moderate' (weighted mean $\mathrm{SMD}_{\text {between }}$ $=1.00,95 \% \mathrm{CI}-0.09$ to 2.10$)$ and ten studies 


\begin{tabular}{|c|c|c|c|c|c|c|c|c|c|}
\hline Study or Subgroup & Std. Mean Difference & SE & $\begin{array}{l}\text { INT } \\
\text { Total }\end{array}$ & $\begin{array}{l}\text { CON } \\
\text { Total }\end{array}$ & Weight & $\begin{array}{l}\text { Std. Mean Difference } \\
\text { N, Random, 95\% Cl }\end{array}$ & \multicolumn{3}{|c|}{$\begin{array}{l}\text { Std. Mean Difference } \\
\text { N, Random, 95\% Cl }\end{array}$} \\
\hline Bellows et al. $2013^{\star a}$ & 0.68 & 0.14 & 99 & 107 & $8.4 \%$ & $0.68[0.41,0.95]$ & & $\rightarrow$ & \\
\hline Bonwin et al. $2013^{*}$ & 0 & 0.08 & 280 & 308 & $9.7 \%$ & $0.00[-0.16,0.16]$ & & & \\
\hline Hardy et al. $2010^{*}$ & 0.53 & 0.11 & 213 & 134 & $9.1 \%$ & $0.53[0.31,0.75]$ & & $\rightarrow$ & \\
\hline Ignico 1991 & 1.73 & 0.44 & 15 & 15 & $3.1 \%$ & $1.73[0.87,2.59]$ & & & \\
\hline Jones et al. $2011^{*}$ & 0.42 & 0.21 & 52 & 45 & $6.8 \%$ & $0.42[0.01,0.83]$ & & $\rightarrow$ & \\
\hline Krombholz 2012 & 0.44 & 0.1 & 211 & 217 & $9.3 \%$ & $0.44[0.24,0.64]$ & & $\rightarrow$ & \\
\hline Piek et al. $2013^{* a}$ & -0.11 & 0.1 & 254 & 196 & $9.3 \%$ & $-0.11[-0.31,0.09]$ & & & \\
\hline Reilly et al. $2006^{*}$ & 0.33 & 0.09 & 231 & 250 & $9.5 \%$ & $0.33[0.15,0.51]$ & & $\rightarrow$ & \\
\hline Roth et al. $2015^{*}$ & 0.62 & 0.17 & 343 & 320 & $7.7 \%$ & $0.62[0.29,0.95]$ & & $\rightarrow$ & \\
\hline Venetsanou \& Kambas 2004 & 0.64 & 0.26 & 28 & 38 & $5.8 \%$ & $0.64[0.13,1.15]$ & & $\longrightarrow$ & \\
\hline Vidoni 2014 & 0.5 & 0.36 & 18 & 15 & $4.1 \%$ & $0.50[-0.21,1.21]$ & & $\rightarrow$ & \\
\hline Yin et al. 2012 & 0.74 & 0.16 & 118 & 69 & $8.0 \%$ & $0.74[0.43,1.05]$ & & $\rightarrow$ & \\
\hline Zasket al. $2012^{\star}$ & 0.54 & 0.11 & 241 & 133 & $9.1 \%$ & $0.54[0.32,0.76]$ & & $\rightarrow$ & \\
\hline Total (95吵 Cl) & & & 2103 & 1847 & 100.0颔 & $0.46[0.28,0.65]$ & & & \\
\hline $\begin{array}{l}\text { Heterogeneity: Tau }=0.08 ; \mathrm{Cl} \\
\text { Test for owerall effect: } Z=4.98\end{array}$ & $\begin{array}{l}=72.13, \mathrm{df}=12(\mathrm{P}<0 . \\
=0.00001)\end{array}$ & 0000 & $i^{2}=8$ & & & & $\begin{array}{c}-2 \\
\text { Favours [CoN] }\end{array}$ & $\begin{array}{lc}0 & 2 \\
\text { Fawours [INT] }\end{array}$ & 4 \\
\hline
\end{tabular}

b

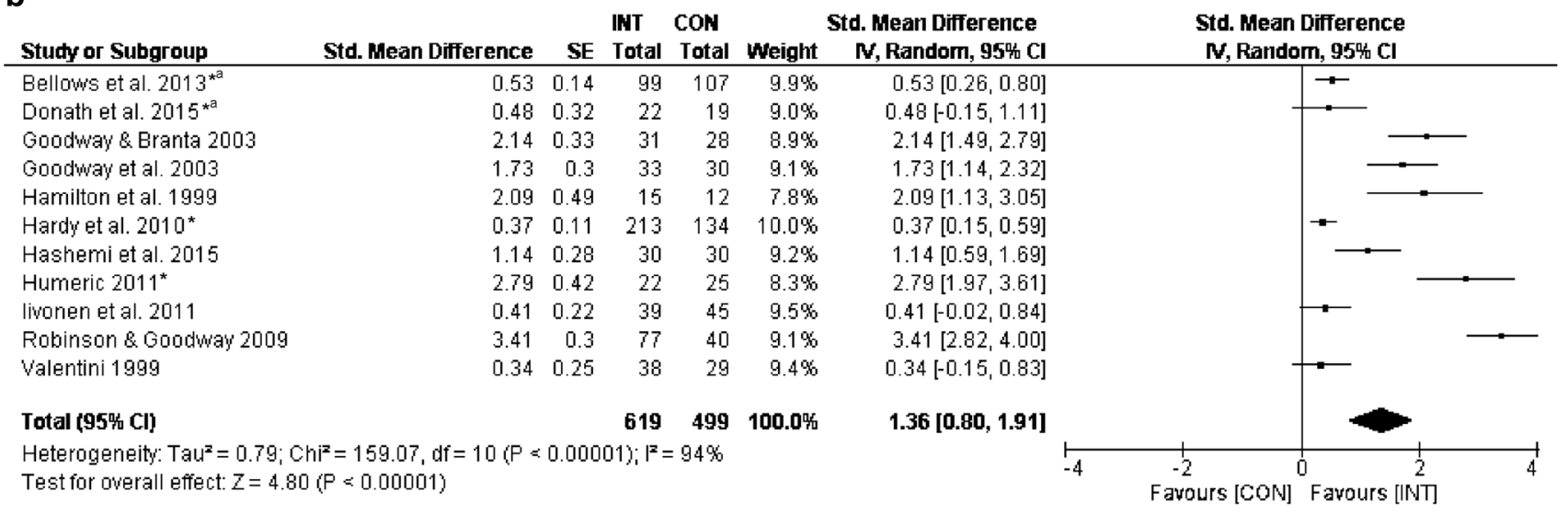

C

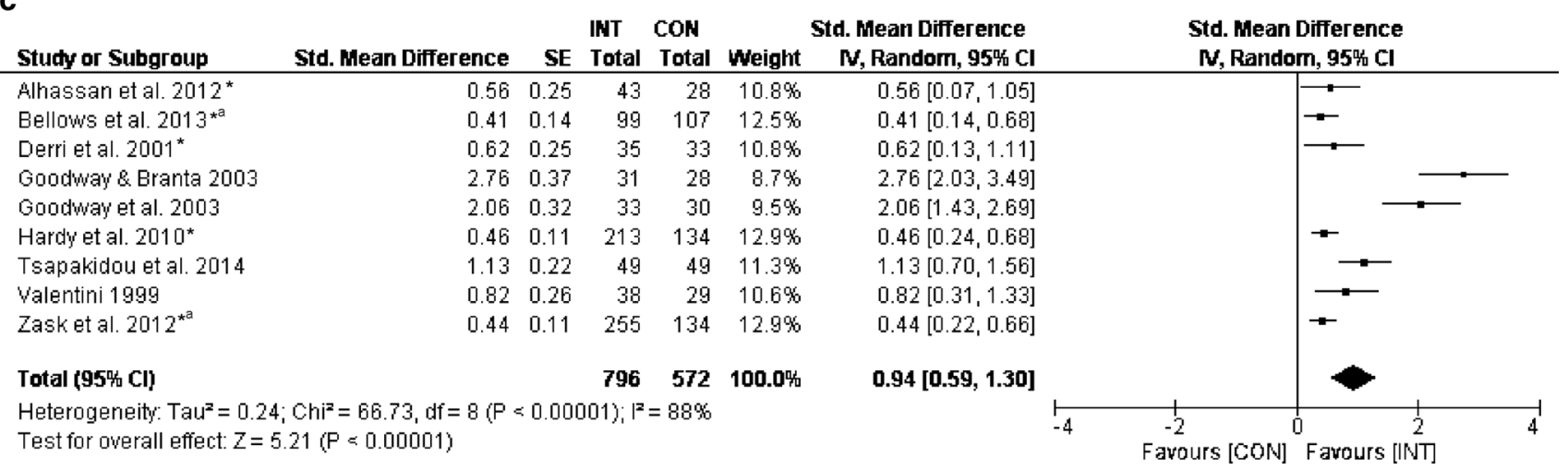

Fig. 2 Effects of fundamental movement skills (FMS) interventions on a total FMS score (40-point scale, higher score is better), b object control subscale (OCS; 20-point scale, higher score is better), and c locomotor subscale (LMS; 20-point scale, higher score is better). CI

[39, 41, 44, 46, 54, 62, 68, 70, 73, 74] with 'weak' (weighted mean $\mathrm{SMD}_{\text {between }}=0.27,95 \% \mathrm{CI}-0.64$ to 1.18) methodological quality showed no statistically significant differences in effect sizes on overall FMS compared with the seven studies [38, 40, 45, 51, 69, 72, 75] of confidence interval, $C O N$ control group, INT intervention group, $I V$ inverse variance, $S E$ standard error, Std standardized, *randomized controlled trial, additional information from author

'high' methodological quality. For total FMS we compared studies that used the TGMD-2 test versus others that used different tests. There was no significant difference in effect sizes between the four studies [40, 41, 49, 75] that used the TGMD-2 and the nine studies [36, 43-45, 52, 
Table 2 GRADE evidence profiles: fundamental movement skills (FMS) enhancing intervention versus usual care

\begin{tabular}{|c|c|c|c|c|c|c|c|c|c|c|c|}
\hline \multicolumn{7}{|c|}{ Quality assessment } & \multicolumn{2}{|c|}{$\begin{array}{l}\text { No. of } \\
\text { participants }\end{array}$} & \multirow{2}{*}{$\begin{array}{l}\text { Absolute } \\
\text { effect }(95 \% \\
\text { CI) }{ }^{\mathrm{f}}\end{array}$} & \multirow[t]{2}{*}{ Quality } & \multirow[t]{2}{*}{ Importance } \\
\hline $\begin{array}{l}\text { No. of } \\
\text { studies }\end{array}$ & $\begin{array}{l}\text { Study } \\
\text { design }\end{array}$ & $\begin{array}{l}\text { Risk of } \\
\text { bias }\end{array}$ & Inconsistency & Indirectness & Imprecision & $\begin{array}{l}\text { Other } \\
\text { considerations }\end{array}$ & INT & $\mathrm{CON}$ & & & \\
\hline
\end{tabular}

Overall FMS (follow-up: range 6 weeks to 20 months; assessed with or converted to TGMD-2; standard score from 2 to 40)

$16 \quad \begin{gathered}\text { RCT } \\ \text { and }\end{gathered}$
CT

OCS (follow-up: range 6 weeks to 8 months; assessed with or converted to TGMD-2; standard score from 1 to 20)

\begin{tabular}{|c|c|c|c|c|c|c|c|c|c|}
\hline $\begin{array}{l}\text { RCT } \\
\text { and } \\
\text { CT }\end{array}$ & Serious $^{\mathrm{a}, \mathrm{b}}$ & Serious $^{\mathrm{c}}$ & Serious $^{\mathrm{d}}$ & Not serious & $\begin{array}{l}\text { Publication } \\
\text { bias }^{\mathrm{e}}\end{array}$ & 619 & 499 & $\begin{array}{l}\text { SMD } 1.36 \\
\text { higher } \\
(0.80-1.91 \\
\text { higher })\end{array}$ & $\begin{array}{r}\text { Very } \\
\text { low }\end{array}$ \\
\hline
\end{tabular}

LMS (follow-up: range 6 weeks to 11 months; assessed with or converted to TGMD-2; standard score from 1 to 20)

$10 \quad \begin{gathered}\text { RCT } \\ \text { and }\end{gathered}$
CT

GRADE Working Group grade of evidence

High quality: We are very confident that the true effect lies close to that of the estimate of the effect

Moderate quality: We are moderately confident in the effect estimate: the true effect is likely to be close to the estimate of the effect, but there is a possibility that it is substantially different

Low quality: Our confidence in the effect is limited: the true effect may be substantially different from the estimate of the effect

Very low quality: We have very little confidence in the effect estimate: the true effect is likely to be substantially different from the estimate of the effect

$C I$ confidence interval, $C O N$ control group, $C T$ controlled trial, GRADE Grading of Recommendations Assessment, Development, and Evaluation System, INT intervention group, LMS Locomotor Subscale, OCS Object Control Subscale, RCT randomized controlled trial, SMD standardized mean difference

${ }^{a}$ Serious because of no clear randomization procedures described

b Serious because of selection bias (unclear or inadequate allocation concealment), detection bias (unclear blinding of data analysts), study integrity (unclear compliance with the intervention)

${ }^{c}$ Serious because of statistical heterogeneity $\left(I^{2}=83-88 \% ; p<0.0001\right)$

${ }^{\mathrm{d}}$ Serious because of important differences in implementation across settings

e Serious because publication bias possible

f 3 and 1 studies for overall FMS and LMS scores, respectively, could not be included in meta-analyses

$68,69,72,73]$ that used another test (weighted mean $\mathrm{SMD}_{\text {between }}=0.72,95 \% \mathrm{CI}-0.50$ to 1.94$)$.

\subsubsection{Exploratory Analyses}

Nine $[41,44-46,49,51,54,61,62]$ out of 30 studies in this systematic review looked at some aspects of gender differences but results were too heterogeneous to run metaanalyses. Effects in girls compared with boys for total FMS were larger in three [41, 45, 49] and smaller in one study [44]. For locomotor skills, no difference in effect sizes were found between the sexes in three studies [46, 61, 62]. However, consistently larger effects were found for object control skills in boys compared with girls in four studies [51, 54, 61, 62]. There was no clear picture regarding characteristics of the interventions (frequency, duration), target population (disadvantaged children, age) or setting (childcare, kindergarten) that explained gender differences in results. Four studies [39, 60-62] included disadvantaged children or children that were at risk of delay in FMS competence due to socioeconomic or biological factors. Three of these studies [39, 60, 61] showed particularly large effect sizes $\left(\mathrm{SMD}_{\text {between }}\right)$ for $\mathrm{LMS}$ and OCS (2.06-2.76).

Figure $3 \mathrm{c}$ shows the intervention effects according to the persons who implemented the FMS intervention in childcares or kindergartens. The 11 studies $[38,39,41$, $51,52,55,60-62,67,73]$ in which external experts implemented the intervention programs compared with the 12 studies [36, 40, 43-46, 49, 54, 68, 69, 72, 75] in which 




Study duration (months)

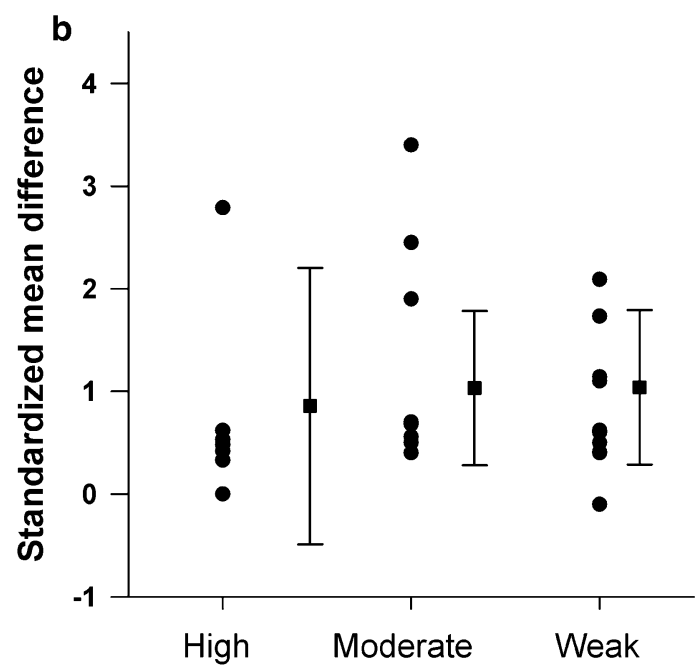

Methodological quality



4Fig. 3 Effect sizes of fundamental movement skill (FMS) interventions according to a duration, $\mathbf{b}$ methodological quality, and $\mathbf{c}$ study execution of included studies. Filled circles illustrate standardized mean differences $\left(\mathrm{SMD}_{\text {between }}\right)$ between intervention and control group for single studies. The filled squares represent weighted mean $\mathrm{SMD}_{\text {between }}$ with $95 \%$ confidence intervals (CI) of the studies combined. The figures show a statistically significant higher effect sizes on overall FMS in favor of studies with shorter duration $\left(\mathrm{SMD}_{\text {between }}=1.23,95 \% \mathrm{CI} 0.86-1.61\right)$ compared with studies with longer duration $\left(\mathrm{SMD}_{\text {between }}=0.32,95 \%\right.$ CI $\left.0.12-0.52\right)$; b no statistically significant differences in effect sizes on overall FMS for studies of 'high' methodological quality $\left(\mathrm{SMD}_{\text {between }}=0.59\right.$, 95\% CI 0.26-0.93) compared with studies with 'moderate' $\left(\mathrm{SMD}_{\text {between }}=1.31,95 \% \mathrm{CI} 0.74-1.88\right)$ and 'weak' $\left(\mathrm{SMD}_{\text {between }}=\right.$ $0.76,95 \%$ CI $0.40-1.11)$ methodological quality; and c statistically significant higher effect sizes on overall FMS in favor of studies with external experts $\left(\mathrm{SMD}_{\text {between }}=1.54,95 \%\right.$ CI $\left.0.93-2.15\right)$ compared with childcare staff $\left(\mathrm{SMD}_{\text {between }}=0.41,95 \%\right.$ CI $\left.0.23-0.59\right)$

childcare or kindergarten teachers were responsible for implementation showed statistically significant higher effect sizes on overall FMS (weighted mean $\mathrm{SMD}_{\text {between }}=1.46,95 \%$ CI $0.52-2.40$ ). For five studies [37, 42, 47, 48, 71], results were not available due to missing SMD, SD, and/or SE or due to the reporting of only single items. Whether studies were more or less effective was not differentiated by either the setting where FMS interventions took place (kindergarten versus childcare), the use of a theoretical framework on which the intervention was based (yes versus no), or the additional involvement of parents in FMS intervention programs (yes versus no) (data not shown). In addition, we were unable to tease out the most effective intervention approach based on pedagogic concept, the volume or the content of the interventions to improve and develop FMS.

\section{Discussion}

Our systematic review and meta-analyses revealed beneficial effects on overall motor skill proficiency (total FMS score), as well as on object control and locomotor skills in children aged 2-6 years with small-to-large effect sizes following FMS intervention programs conducted in childcare or kindergarten settings. Further, studies of shorter ( $<6$ months) compared with longer duration ( $\geq 6$ months) and the integration of external experts rather than implementation of the programs by the usual childcare/kindergarten teachers resulted in higher effect sizes, while the methodological quality of the studies did not play a role. Importantly, due to the low certainty of evidence based on GRADE, findings of this systematic review and metaanalysis have to be interpreted with care. Even though most studies conducted in childcare and kindergarten proved to 
be effective, we have to acknowledge that the effect estimates and the true effect may likely be substantially different from the current effect estimates as reported in this review. This finding should by no means be interpreted as that FMS interventions in young children should not be done as there is insufficient evidence, but rather, it should be taken as a key message that more high-quality research is needed in the field of FMS interventions in early childhood [76]. A higher quality of studies would imply highstandard randomization procedures, the careful selection of control groups to prevent cross-contamination [77, 78], the integration of appropriate power analyses to calculate sample sizes needed for group or sub-group analyses (e.g., for gender), and the blinding of assessors for important outcomes such as FMS [79, 80]. Further, it seems imperative and timely to carefully select and standardize test batteries for FMS assessment [81], to use adequate statistical methods including appropriate baseline comparisons as well as the control for important confounders and clusters [82], to assess intervention fidelity [83], and finally to integrate long-term follow-up [84].

\subsection{Interpretation of Overall, Subgroup, and Exploratory Analyses}

Despite our comprehensive search in seven databases from the year of inception up to August 2015, only 30 studies fulfilled our eligibility criteria, 15 of which $[37,39,41-43,46-48,52,54,60-62,73,74]$ were CTs rather than RCTs. There was, however, no major difference in findings and effect sizes between CTs or RCTs (data not shown). Contrary to physiological considerations of a doseresponse principle with the expectation that longer interventions would lead to higher effect sizes, we found that longer interventions showed smaller effect sizes (Fig. 3a). This trend was also documented in other reviews [31] and suggests that a loss of compliance and motivation may have occurred with activities provided during FMS interventions becoming monotonous and leading children and caregivers to lose interest over time [25]. Alternatively, there may have been insufficient adaption of the programs, which need training progression over time to keep up a stimulus $[85,86]$.

The methodological quality of the studies was not proportional to the effect sizes of the intervention on FMS (Fig. 3b), suggesting that an overestimation of training on FMS in preschoolers did not occur. It is also reassuring that the overall picture of beneficial effects of interventions on overall FMS, OCS, and LMS was consistent and in accordance with other reviews focusing on children with developmental delays $[27,28]$ or on children with an older age range $[25,26]$. Even in the single test items, findings revealed medium (jumping, throwing, catching, kicking) or at least small (running, hopping, standing long jump, balance) effect sizes. Yet, based on GRADE (Table 2), where we assessed the magnitude of effects and the overall quality of evidence and found that the estimates of FMS interventions in young children are trustworthy, we have little confidence in the effect estimates and it is therefore very probable that the true effect is likely substantially smaller or larger than the effect estimate. Of the five relevant factors that can lower the quality of evidence, four factors showed serious limitations. These included the failure of describing the detailed study design and execution or risk of bias (e.g., no clear description of randomization procedures), the finding of inconsistency or heterogeneity of effects (e.g., statistical heterogeneity of effects with $I^{2}>80 \%$ all outcomes), indirectness or applicability (e.g., important differences in implementation across settings), and a possible publication bias (ESM Fig. S1). Smaller estimates of effects of FMS interventions may, for instance, be found if assessors of FMS are blinded for group assignments [79, 80], while larger effects may be found if fidelity regarding the implementation of the intervention is assessed [83], or by the selection of proper control groups without cross-contamination [77, 78].

Although some argue that long-term follow-ups are most relevant when studies show short-term effects, follow-ups should be contingent on the methodological quality of the original trial, irrespective of effect [76]. In this review, only seven $[44,45,51,54,55,62,72]$ of 30 studies included longer-term follow-ups. Of those, three studies $[51,55,72]$ provided evidence of sustained beneficial effects on FMS 8-12 weeks off intervention $\left(\mathrm{SMD}_{\text {between }}=1.80, \quad 95 \%\right.$ CI $1.03-2.57 ; \quad \mathrm{SMD}_{\text {between }}$ $=0.59,95 \% \mathrm{CI} 0.17-1.01 ; \mathrm{SMD}_{\text {between }}=2.67,95 \% \mathrm{CI}$ 2.15-3.19), while four studies [44, 45, 54, 62] with followup from 3-12 months off intervention did not find lasting effects. This finding supports the opinion of experts in the field that FMS have to be taught, practiced, and reinforced repeatedly as they do not seem to develop and be maintained naturally [26, 31, 32]. However, it may be a challenge to find feasible and effective strategies that lead to a sustained FMS proficiency in view of the fading effects with longer-term interventions and the obvious need for experienced teachers.

In order to help us better understand which intervention strategies may or may not work, why, and for whom, we tried to tease out interventions that were more effective than others by stratifying for target groups, the setting, and characteristics of the interventions. Although trials were only included if they examined typically developing young children, four studies [39, 60-62] included disadvantaged children or children that were at risk of delay in FMS competence due to socioeconomic or biological factors. Three studies $[39,60,61]$ showed particularly large effect 
sizes $\left(\mathrm{SMD}_{\text {between }}\right)$ for LMS and OCS (2.06-2.76), possibly because these children may have had greater potential to improve FMS competence [31]. On the other hand, interventions targeting a completely healthy population of young children may have the problem of attaining a ceiling effect in FMS proficiency. This could be the case when FMS interventions use an FMS outcome test that is mainly built to differentiate typically developing children from those with a motor deficiency rather than having the potential to differentiate skills within a healthy population [8]. We do not think that this phenomenon has occurred, as in our review, effect sizes for total FMS among those studies that started with mean values below the median at baseline were not different from those that started with above-median values $\left(\mathrm{SMD}_{\text {between }}=1.01,95 \% \mathrm{CI}-0.11\right.$ to 2.29). A ceiling effect for FMS intervention results may also be more likely when the age of the target group children is close to the upper limit of the validated age range that is covered by the respective test battery [81]. This was not the case in most studies in this review. Firstly, they used scaled scores or percentiles for age categories based on half-yearly or yearly steps to adjust for age and maturational effects; and secondly, they used predominantly the TGMD(-2), which covers ages up to 10 years. Nevertheless, several tests that were also used in the included studies have an upper age limit of 6 years (see ESM Table S2), where a ceiling effect might have played a role. As studies usually report mean ages and SDs, the ceiling effect is difficult to assess, but should indeed be considered in future studies.

Although clear gender differences for FMS exist $[15,87,88]$, be it related to differences in physical activity behavior [89] or cultural norms [8] that may foster enhanced FMS in boys (e.g., kicking) or girls (e.g., balancing), the reach and responsiveness of girls and boys in interventions targeting FMS may be different as well. Only a few studies in this review scrutinized gender differences. They reported unequivocal results for total FMS (one study [44] with higher effect sizes in boys and three studies [41, 45, 49] with higher effect sizes in girls), consistently better results for object control skills favoring boys (four studies $[51,54,61,62])$, but no difference in effects for locomotor skills (three studies [46, 61, 62]). Although recent primary research focusing on FMS indicated that gender differences in FMS existed in favor of the boys [90-93], FMS was a predictor of physical activity and fitness in adolescence in both sexes [6,94]. The few genderdifferentiated results in our systematic review did not allow for conclusions to be drawn on whether girls or boys profited more from FMS interventions or whether there is a need for and value to be gained from targeting. So far, both sexes seem to profit from FMS interventions. It may be that boys profit more from interventions targeting object control skills, as consistently stronger effects in favor of boys were found in our review [51, 54, 61, 62]. Perceived competence, whether preceded [95] or as a consequence of actual (motor) competence [96], may have played a role in their motivation to improve object control skills [97, 98]. However, evidence of a gender difference in the association between actual and perceived FMS in young children is lacking [99]. As Barnett et al. [90] suggested, boys may simply obtain more encouragement, positive reinforcement, and stimulation for activities involving object control skills.

Future consideration should therefore be given to the need for a universal or gender-targeted approach, the acceptability and effectiveness of different approaches available for targeting, and the potential positive and negative consequences of either [76].

While the setting (kindergarten versus childcare) did not play a role in effectiveness, effects were stronger when the intervention was provided by an external expert in the field of FMS rather than the usual childcare or kindergarten teachers (Fig. 3c). The integration of experts to build up proper FMS programs and educate childcare and kindergarten teams how to teach FMS [100] seems evident [55]. These experts bring the combined expertise of knowledge about the development and training of FMS and the pedagogic skills needed to foster actual but also perceived FMS [100]. They may also be more skilled at providing the magic intervention ingredient of fun that is identified as a critical component of interventions [101, 102] and that may lead to sustained enjoyment $[103,104]$ and create a motivational climate for teachers and the children [62]. Promising concepts have been used by the integrated studies attempting to integrate these fundamental psychological and pedagogic principles, including programs that specifically focused on a mastery climate [55], or integrated music and dance $[37,46,62,68,70]$. Whatever the concept, an intervention delivering on sustained fun is likely to engage children as well as teachers and promote ongoing involvement, while being enjoyable to deliver [76].

\subsection{Strengths and Limitations}

Our review has several strengths. We reviewed all intervention studies aimed at increasing motor skills in young children by including a larger range of literature databases than other reviews [26, 31, 32]. The focus was on typically developing young children attending childcare or kindergarten in contrast to mainly school-aged individuals $[25,26]$ and did not include children with existing motor handicaps or with developmental delays [27, 28]. Teams of reviewers worked both independently and in pairs to select eligible studies, assess risk of bias and extract data. Furthermore, we used the GRADE approach to rate our 
certainty in the evidence and presented findings with the GRADE evidence profiles. Our results are limited by shortcomings of many of the studies that were eligible for our review and led to our ratings of very low certainty for the intervention effects. Reasons for downgrading included limitations in the study design such as CTs or RCTs with unclear randomization procedures and lack of information regarding allocation concealment, and lack of blinding of outcome assessors and data analysts. Moreover, there was a huge variation in intervention content, duration, and intensity, and often an unknown intervention integrity that did not lead to any sort of dose-response in the outcomes [65]. In addition, there was a large heterogeneity of results. This heterogeneity of results may be explained at least in part by the substantial variation in intervention load and strategies, by the use of a wide range of motor test batteries to measure motor skills [105], or by a high chance of a publication bias. The latter is shown in the consistently asymmetrical funnel plots for the overall FMS and the subscales [106] (ESM Fig. S1) and verified by the Egger's test [107] (data not shown). The activities in the control group were poorly defined in 19 out of 30 studies, providing room for bias [77, 78]. Further limitations were the exclusion of studies written in languages other than English or German, the skipping of the forward tracking of studies (e.g., looking at studies that cite the included articles), and the conversion of the motor skill test results to the most commonly used test battery among the eligible studies of this review as suggested by GRADE [66]. These applied motor skill test batteries may appear to measure similar constructs and show high correlations in change scores; however, responsiveness of instruments may differ substantially and lead to important between-study heterogeneity [108]. Nevertheless, in our review effect sizes for total FMS were similar in studies that used the reference test (TGMD[-2]) versus those that used another test, suggesting the different responsiveness was not a major problem. Moreover, the use of process-oriented FMS tests that measure how (well) a movement skill is measured or product-oriented FMS assessment batteries in which quantity aspects (e.g., time or distance) are measured provide diverging information [81]. Although the two means of assessment are reasonably related, they also show substantial variation of correlations that may have affected the pooled results in meta-analyses $[8,81]$.

\subsection{Implications for Clinical Practice}

From a very young age, proficiency in FMS is related to relevant aspects of health including higher physical activity and physical fitness, reduced obesity, and enhanced social and cognitive skills [11, 109]. Developing motor skills enables the young child to interact with the social and physical environment. As children grow, motor skills are crucial to engage in a large variety of movements and play activities, starting with simple running or throwing a ball to complex physical interactions with peers in the playground or during (organized) sports. Moreover, mutual interactions between motor and cognitive performance and executive functions take place $[110,111]$ and motor control is used to guide the way in which the surroundings are perceived and processed through ongoing interactions between brain, body, and environment [112]. Thus, improving actual motor skill development, but also perceived motor competence may provide enhanced opportunities for the development of a variety of perceptual, social, and cognitive skills, and may further be influenced in turn by these abilities in iterative interactive cycles [9, 98, 113, 114]. Given these clinically relevant and plausible benefits, improving actual and perceived motor skills should be a priority public health strategy to stimulate physical activity in youth, ideally implemented at the childcare or kindergarten level where a large number of young children can be reached very early $[9,31,32]$ and without stigmatization of those that need it most.

Based on this and previous reviews [26, 31, 32], all aspects of FMS should and can be taught in childcare, kindergarten, or similar settings, including object control skills, locomotor skills, balance, or more complex FMS tasks (see Fig. 2 and ESM Figs. S2-4), preferably by the integration of an expert teacher [55] and by intervening over time [26, 31, 32]. Careful emphasis should be placed on maintaining attractive and potent intervention programs for children and teachers as effects may fade with time due to a loss of motivation or insufficient physical stimulus. To progress the field, more theory-driven research [9] needs to be done to tease out the most effective intervention components (length and intensity of sessions, timing, duration, content, context such as with or without music, the integration of dance items), as well as possible effect modifications by age [115], gender [116], obesity [15], physical activity [10], perceived motor competence [97, 117], physical fitness [14], characteristics of the setting [69], and teachers [15].

Scientifically, the best strategy to improve FMS in young children has yet to be determined in future studies that will hopefully address current limitations. The conduct and publication of well-designed evaluations of well-defined interventions using the same standardized assessment tool for young children, preferably combining process- and product-oriented FMS test items [81], with international reference values allowing direct comparison (also of intervention effects) worldwide is crucial to advance the field of FMS promotion in children and help us better understand which intervention strategies may or may not work, why, and for whom [76]. Consequently, this may 
then lead to realistic and clinically sound implementation strategies to foster FMS proficiency starting at an early age.

\section{Conclusion}

This review indicates positive effects of childcare- or kindergarten-based interventions on FMS proficiency in young children. Yet, the evidence base is low and we have little confidence in the effect estimate. As the true effect is likely to be substantially different from the reported estimate of the effect, results must be considered with care. Nevertheless, FMS-enhancing programs may have an important role in children attaining motor skill proficiency as the basis for a physically active lifestyle [6] and to profit from a variety of physiological, social, and cognitive health benefits [11, 118]. Future high-quality research is needed to establish certainty in effectiveness of FMS training in young children by searching for optimal programs, looking at dose-response relations and long-term sustainability.

Additional references can be found in the ESM $[8,33,36,37,88,119-132]$.

Acknowledgements We greatly thank Dr Gosteli for her professional support in the literature search. We also thank Prof. Puhan for his critical comments and inputs for the review.

\section{Compliance with Ethical Standards}

Funding Source The review was partially funded through a Sinergia grant from the SNF (Grant Number: CRSII3_147673) (http://p3.snf. ch/project-147673) and by the Jacobs Foundation.

Financial Disclosure The authors have no financial relationships relevant to this article to disclose.

Conflict of Interest Kristin Wick, Claudia Leeger-Aschmann, Nico D. Monn, Thomas Radtke, Laura V. Ott, Cornelia E. Rebholz, Sergio Cruz, Natalie Gerber, Einat A. Schmutz, Jardena J Puder, Simone Munsch, Tanja H. Kakebeeke, Oskar G. Jenni, Urs Granacher, and Susi Kriemler declare that they have no conflict of interest relevant to this article to disclose.

Open Access This article is distributed under the terms of the Creative Commons Attribution 4.0 International License (http:// creativecommons.org/licenses/by/4.0/), which permits unrestricted use, distribution, and reproduction in any medium, provided you give appropriate credit to the original author(s) and the source, provide a link to the Creative Commons license, and indicate if changes were made.

\section{References}

1. Gallague D, Ozmun J. Understanding motor development: infants, children, adolescents, adults. Boston: McGraw-Hill; 2006.

2. Haywood K, Getchell N. Life span motor development. Champaign: Human Kinetics; 2003.
3. Lloyd RS, Oliver JL, Faigenbaum AD, Howard R, De Ste Croix $\mathrm{MB}$, Williams CA, et al. Long-term athletic development- part 1: a pathway for all youth. J Strength Cond Res. 2015;29(5):1439-50.

4. Lloyd RS, Cronin JB, Faigenbaum AD, Haff GG, Howard R, Kraemer WJ, et al. National strength and conditioning association position statement on long-term athletic development. J Strength Cond Res. 2016;30(6):1491-509.

5. Payne G, Isaacs D. Human motor development: a lifestyle approach. 8th ed. London: Mayfield Publishing Company; 2012.

6. Barnett LM, Van Beurden E, Morgan PJ, Brooks LO, Beard JR. Childhood motor skill proficiency as a predictor of adolescent physical activity. J Adolesc Health. 2009;44(3):252-9.

7. Burton AW, Miller DE. Movement skill assessment. Minnesota: Human Kinetics; 1998.

8. Cools W, Martelaer KD, Samaey C, Andries C. Movement skill assessment of typically developing preschool children: a review of seven movement skill assessment tools. J Sports Sci Med. 2009;8(2):154-68.

9. Robinson LE, Stodden DF, Barnett LM, Lopes VP, Logan SW, Rodrigues LP, et al. Motor competence and its effect on positive developmental trajectories of health. Sports Med. 2015;45(9): 1273-84.

10. Stodden DF, Goodway JD, Langendorfer SJ, Roberton MA, Rudisill ME, Garcia C, et al. A developmental perspective on the role of motor skill competence in physical activity: an emergent relationship. Quest. 2008;60(2):290-306.

11. Lubans DR, Morgan PJ, Cliff DP, Barnett LM, Okely AD. Fundamental movement skills in children and adolescents: review of associated health benefits. Sports Med. 2010;40(12):1019-35.

12. Seefeldt V. Developmental motor patterns: implications for elementary school physical fitness. In: Nadeau $\mathrm{CH}$, Halliwell WR, Newell KC, et al., editors. Psychology of motor behavior and sport. Champaign: Human Kinetics; 1980. p. 314-23.

13. Logan SW, Kipling Webster E, Getchell N, Pfeiffer KA, Robinson LE. Relationship between fundamental motor skill competence and physical activity during childhood and adolescence: a systematic review. Kinesiol Rev. 2015;4(4):416-26.

14. Cattuzzo MT, Dos Santos Henrique R, Re AH, de Oliveira IS, Melo BM, de Sousa Moura M, et al. Motor competence and health related physical fitness in youth: a systematic review. J Sci Med Sport. 2016;19(2):123-9.

15. Barnett LM, Lai SK, Veldman SL, Hardy LL, Cliff DP, Morgan $\mathrm{PJ}$, et al. Correlates of gross motor competence in children and adolescents: a systematic review and meta-analysis. Sports Med. 2016;46(11):1663-88.

16. D'Hondt E, Deforche B, Gentier I, De Bourdeaudhuij I, Vaeyens $\mathrm{R}$, Philippaerts R, et al. A longitudinal analysis of gross motor coordination in overweight and obese children versus normalweight peers. Int J Obes (Lond). 2013;37(1):61-7.

17. D'Hondt E, Deforche B, Gentier I, Verstuyf J, Vaeyens R, De Bourdeaudhuij I, et al. A longitudinal study of gross motor coordination and weight status in children. Obesity (Silver Spring). 2014;22(6):1505-11.

18. Bryant ES, Duncan MJ, Birch SL. Fundamental movement skills and weight status in British primary school children. Eur J Sport Sci. 2014;14(7):730-6.

19. Erwin HE, Castelli DM. National physical education standards: a summary of student performance and its correlates. Res Q Exerc Sport. 2008;79(4):495-505.

20. Hardy LL, Barnett L, Espinel P, Okely AD. Thirteen-year trends in child and adolescent fundamental movement skills: 1997-2010. Med Sci Sports Exerc. 2013;45(10):1965-70.

21. Haapala EA. Cardiorespiratory fitness and motor skills in relation to cognition and academic performance in children-a review. J Hum Kinet. 2013;36:55-68. 
22. Gabbard C. A developmental systems approach to the study of motor development. In: Pelligrino LT, editor. Handbook of motor skills: development, impairment and therapy. Hauppauge: Nova Science Publisher; 2009. p. 259-68.

23. Williams HG, Pfeiffer KA, O’Neill JR, Dowda M, McIver KL, Brown WH, et al. Motor skill performance and physical activity in preschool children. Obesity. 2008;16(6):1421-6.

24. Babic MJ, Morgan PJ, Plotnikoff RC, Lonsdale C, White RL, Lubans DR. Physical activity and physical self-concept in youth: systematic review and meta-analysis. Sports Med. 2014;44(11): 1589-601.

25. Lai SK, Costigan SA, Morgan PJ, Lubans DR, Stodden DF, Salmon $\mathrm{J}$, et al. Do school-based interventions focusing on physical activity, fitness, or fundamental movement skill competency produce a sustained impact in these outcomes in children and adolescents? A systematic review of follow-up studies. Sports Med. 2014;44(1):67-79.

26. Morgan PJ, Barnett LM, Cliff DP, Okely AD, Scott HA, Cohen $\mathrm{KE}$, et al. Fundamental movement skill interventions in youth: a systematic review and meta-analysis. Pediatrics. 2013;132(5): e1361-83.

27. Pless M, Carlsson M, Sundelin C, Persson K. Effects of group motor skill intervention on five- to six-year-old children with developmental coordination disorder. Pediatr Phys Ther. 2000;12(4):183-9.

28. Smits-Engelsman BCM, Blank R, Van der Kaay AC, MosterdVan der Meijs R, Vlugt-Van den Brand E, Polatajko HJ, et al. Efficacy of interventions to improve motor performance in children with developmental coordination disorder: a combined systematic review and meta-analysis. Dev Med Child Neurol. 2013;55(3):229-37.

29. Ling J, Robbins LB, Wen F, Peng W. Interventions to increase physical activity in children aged 2-5 years: a systematic review. Pediatr Exerc Sci. 2015;27(3):314-33.

30. Mehtälä MA, Saakslahti AK, Inkinen ME, Poskiparta ME. A socio-ecological approach to physical activity interventions in childcare: a systematic review. Int $\mathrm{J}$ Behav Nutr Phys Act. 2014;11:22-33.

31. Logan SW, Robinson LE, Wilson AE, Lucas WA. Getting the fundamentals of movement: a meta-analysis of the effectiveness of motor skill interventions in children. Child Care Health Dev. 2012;38(3):305-15.

32. Riethmuller AM, Jones R, Okely AD. Efficacy of interventions to improve motor development in young children: a systematic review. Pediatrics. 2009;124(4):e782-92.

33. Moher D, Liberati A, Tetzlaff J, Altman DG, Group P. Preferred reporting items for systematic reviews and meta-analyses: the PRISMA statement. PLoS Med. 2009;6(7):e1000097.

34. Liberati A, Altman DG, Tetzlaff J, Mulrow C, Gotzsche PC, Ioannidis JP, et al. The PRISMA statement for reporting systematic reviews and meta-analyses of studies that evaluate healthcare interventions: explanation and elaboration. BMJ. 2009;339:b2700.

35. Deeks JJ, Dinnes J, D'Amico R, Sowden AJ, Sakarovitch C, Song F, et al. Evaluating non-randomised intervention studies. Health Technol Assess. 2003;7(27):iii-x, 1-173.

36. Bellows LL, Davies PL, Anderson J, Kennedy C. Effectiveness of a physical activity intervention for Head Start preschoolers: a randomized intervention study. Am J Occup Ther. 2013;67(1):28-36.

37. Deli E. Implementing intervention movement programs for kindergarten children. J Child Res. 2006;4(1):5-18.

38. Donath L, Faude O, Hagmann S, Roth R, Zahner L. Fundamental movement skills in preschoolers: a randomized controlled trial targeting object control proficiency. Child Care Health Dev. 2015;41(6):1179-87.
39. Hamilton M, Goodway J, Haubenstricker J. Parent-assisted instruction in a motor skill program for at-risk preschool children. Adapt Phys Act Q. 1999;16(4):415-26.

40. Hardy LL, King L, Kelly B, Farrell L, Howlett S. Munch and move: evaluation of a preschool healthy eating and movement skill program. Int J Behav Nutr Phys Act. 2010;7:80-90.

41. Ignico A. Effects of a competency-based instruction on kindergarten children's gross motor development. Phys Educ. 1991;48:188-91.

42. Kelly LE, Dagger J, Walkley J. The effects of an assessmentbased physical education program on motor skill development in preschool children. Educ Treat Child. 1989;12(2):152-64.

43. Krombholz H. The impact of a 20-month physical activity intervention in child care centers on motor performance and weight in overweight and healthy-weight preschool children. Percept Mot Skills. 2012;115(3):919-32.

44. Piek JP, McLaren S, Kane R, Jensen L, Dender A, Roberts C, et al. Does the Animal Fun program improve motor performance in children aged 4-6 years? Hum Mov Sci. 2013;32(5):1086-96.

45. Reilly JJ, Kelly L, Montgomery C, Williamson A, Fisher A, $\mathrm{McColl} \mathrm{JH}$, et al. Physical activity to prevent obesity in young children: cluster randomised controlled trial. BMJ. 2006;333(7577):1041-5.

46. Tsapakidou A, Stefanidou S, Tsompanaki E. Locomotor development of children aged 3.5 to 5 years in nursery schools in Greece. Rev Eur Stud. 2014;6(2):1-6.

47. Wang JH-T. A study on gross motor skills of preschool children. J Res Child Educ. 2004;19(1):32-43.

48. Weiss A, Weiss E, Stehle J, Zimmer K, Heck H, Raab P. The influence of a psychomotor training program on the posture and motor skills of children in pre-school age. Dtsch Z Sportmed. 2004;55(4):101-5.

49. Zask A, Adams JK, Brooks LO, Hughes DF. Tooty Fruity Vegie: an obesity prevention intervention evaluation in Australian preschools. Health Promot J Aust. 2012;23(1):10-5.

50. Deeks JJ, Higgins JPT. Statistical algorithms in Review Manager 5. 2010 [cited 2016 February 12th]. Available from: http:// tech.cochrane.org/revman/documentation/Statistical-methods-inRevMan-5.pdf.

51. Hurmeric I. The effects of two motor skill interventions on preschool children's object control skills and their perceived motor competence. USA: ProQuest Information \& Learning; 2011.

52. Yin Z, Parra-Medina D, Cordova A, He M, Trummer V, Sosa E, et al. Miranos! Look at us, we are healthy! An environmental approach to early childhood obesity prevention. Child Obes. 2012;8(5):429-39.

53. Thorlund K, Walter SD, Johnston BC, Furukawa TA, Guyatt GH. Pooling health-related quality of life outcomes in metaanalysis-a tutorial and review of methods for enhancing interpretability. Res Synth Methods. 2011;2(3):188-203.

54. Iivonen S, Sääkslahtia A, Nissinenb K. The development of fundamental motor skills of four- to five-year old preschool children and the effects of a preschool physical education curriculum. Early Child Dev Care. 2011;181(3):335-43.

55. Robinson LE, Goodway JD. Instructional climates in preschool children who are at-risk. Part I: object-control skill development. Res Q Exerc Sport. 2009;80(3):533-42.

56. Higgins JPT, Green S. Cochrane handbook for systematic reviews of interventions. 2011 [cited 2016 February 26th]. Available from: http://handbook.cochrane.org/index.htm-front_ page.htm.

57. Cohen J. Statistical power analysis for the behavioral sciences. Hillsdale: Lawrence Erlbaum Associates; 1988.

58. Bandura A. Social cognitive theory. In: Vasta R, editor. Annals of child development. Greenwich: JAI Press; 1989. p. 1-60. 
59. Prochaska JO, Velicer WF. The transtheoretical model of health behavior change. Am J Health Promot. 1997;12(1):38-48.

60. Goodway JD, Branta CF. Influence of a motor skill intervention on fundamental motor skill development of disadvantaged preschool children. Res Q Exerc Sport. 2003;74(1):36-46.

61. Goodway JD, Crowe H, Ward P. Effects of motor skill instruction on fundamental motor skill development. Adapt Phys Act Q. 2003;20(3):298-314.

62. Valentini NC. Mastery motivational climate motor skill intervention: replication and follow-up. USA: ProQuest Information \& Learning; 1999.

63. Casella G, Berger RL. Statistical inference. 2nd ed. USA: Thomson Learning; 2002.

64. Guyatt G, Oxman AD, Akl EA, Kunz R, Vist G, Brozek J, et al. GRADE guidelines: 1. Introduction-GRADE evidence profiles and summary of findings tables. $\mathrm{J}$ Clin Epidemiol. 2011;64(4):383-94.

65. Guyatt GH, Oxman AD, Sultan S, Glasziou P, Akl EA, AlonsoCoello P, et al. GRADE guidelines: 9. Rating up the quality of evidence. J Clin Epidemiol. 2011;64(12):1311-6.

66. Guyatt GH, Thorlund K, Oxman AD, Walter SD, Patrick D, Furukawa TA, et al. GRADE guidelines: 13. Preparing summary of findings tables and evidence profiles-continuous outcomes. J Clin Epidemiol. 2013;66(2):173-83.

67. Alhassan S, Nwaokelemeh O, Ghazarian M, Roberts J, Mendoza A, Shitole S. Effects of locomotor skill program on minority preschoolers' physical activity levels. Pediatr Exerc Sci. 2012;24(3):435-49.

68. Vidoni C, Hanaki-Martin S, Carter K, Wooten-Burnett S, de Paleville DT. Incorporating a movement skill program into a preschool daily schedule. Res Q Exerc Sport. 2014;85(8):88-9.

69. Bonvin A, Barral J, Kakebeeke TH, Kriemler S, Longchamp A, Schindler C, et al. Effect of a governmentally-led physical activity program on motor skills in young children attending child care centers: a cluster randomized controlled trial. Int J Behav Nutr Phys Act. 2013;10:90-101.

70. Derri V, Tsapakidou A, Zachopoulou E, Kioumourtzoglou E. Effect of a music and movement programme on development of locomotor skills by children 4 to 6 years of age. Eur Phys Educ Rev. 2001;6(1):16-25.

71. Puder JJ, Marques-Vidal P, Schindler C, Zahner L, Niederer I, Bürgi $\mathrm{F}$, et al. Effect of multidimensional lifestyle intervention on fitness and adiposity in predominantly migrant preschool children (Ballabeina): cluster randomised controlled trial. BMJ. 2011;343(7830):d6195.

72. Roth K, Kriemler S, Lehmacher W, Ruf KC, Graf C, Hebestreit $\mathrm{H}$. Effects of a physical activity intervention in preschool children. Med Sci Sports Exerc. 2015;47(12):2542-51.

73. Venetsanou F, Kambas A. How can a traditional Greek dances programme affect the motor proficiency of pre-school children? Res Dance Educ. 2004;5(2):127-38.

74. Hashemi M, Khameneh NN, Salehian MH. Effect of selected games on the development of manipulative skills in 4-6 year-old preschool girls. Med Sport (Roma). 2015;68(1):49-55.

75. Jones RA, Riethmuller A, Hesketh K, Trezise J, Batterham M, Okely AD. Promoting fundamental movement skill development and physical activity in early childhood settings: a cluster randomized controlled trial. Pediatr Exerc Sci. 2011;23(4): $600-15$.

76. van Sluijs EM, Kriemler S. Reflections on physical activity intervention research in young people-dos, don'ts, and critical thoughts. Int J Behav Nutr Phys Act. 2016;13(1):25-30.

77. Waters L, Reeves M, Fjeldsoe B, Eakin E. Control group improvements in physical activity intervention trials and possible explanatory factors: a systematic review. J Phys Act Health. 2012;9(6):884-95.
78. Waters LA, Reeves MM, Fjeldsoe BS, Eakin EG. Characteristics of control group participants who increased their physical activity in a cluster-randomized lifestyle intervention trial. BMC Public Health. 2011;11(11):27.

79. Hrobjartsson A, Thomsen AS, Emanuelsson F, Tendal B, Hilden $\mathrm{J}$, Boutron I, et al. Observer bias in randomized clinical trials with measurement scale outcomes: a systematic review of trials with both blinded and nonblinded assessors. CMAJ. 2013;185(4):E201-11.

80. Wood L, Egger M, Gluud LL, Schulz KF, Juni P, Altman DG, et al. Empirical evidence of bias in treatment effect estimates in controlled trials with different interventions and outcomes: meta-epidemiological study. BMJ. 2008;336(7644):601-5.

81. Logan SW, Barnett LM, Goodway JD, Stodden DF. Comparison of performance on process- and product-oriented assessments of fundamental motor skills across childhood. J Sports Sci. 2016;12:1-8.

82. Campbell MK, Piaggio G, Elbourne DR, Altman DG, Group C. Consort 2010 statement: extension to cluster randomised trials. BMJ. 2012;04(345):e5661.

83. Miller WR, Rollnick S. The effectiveness and ineffectiveness of complex behavioral interventions: impact of treatment fidelity. Contemp Clin Trials. 2014;37(2):234-41.

84. Jones RA, Sinn N, Campbell KJ, Hesketh K, Denney-Wilson E, Morgan PJ, et al. The importance of long-term follow-up in child and adolescent obesity prevention interventions. Int $\mathrm{J}$ Pediatr Obes. 2011;6(3-4):178-81.

85. Faigenbaum AD, Farrell A, Fabiano M, Radler T, Naclerio F, Ratamess NA, et al. Effects of integrative neuromuscular training on fitness performance in children. Pediatr Exerc Sci. 2011;23(4):573-84.

86. Matos N, Winsley RJ. Trainability of young athletes and overtraining. J Sports Sci Med. 2007;6(3):353-67.

87. Pedersen AV, Sigmundsson H, Whiting HT, Ingvaldsen RP. Sex differences in lateralisation of fine manual skills in children. Exp Brain Res. 2003;149(2):249-51.

88. Ulrich DA. Test of gross motor development. 2nd ed. Austin: Pro-Ed; 2000.

89. Cooper AR, Goodman A, Page AS, Sherar LB, Esliger DW, van Sluijs EM, et al. Objectively measured physical activity and sedentary time in youth: the International children's accelerometry database (ICAD). Int $J$ Behav Nutr Phys Act. 2015; 12:113.

90. Barnett LM, van Beurden E, Morgan PJ, Brooks LO, Beard JR. Gender differences in motor skill proficiency from childhood to adolescence: a longitudinal study. Res Q Exerc Sport. 2010;81(2): 162-70.

91. Goodway JD, Robinson LE, Crowe H. Gender differences in fundamental motor skill development in disadvantaged preschoolers from two geographical regions. Res Q Exerc Sport. 2010;81(1):17-24.

92. Hume C, Okely A, Bagley S, Telford A, Booth M, Crawford D, et al. Does weight status influence associations between children's fundamental movement skills and physical activity? Res Q Exerc Sport. 2008;79(2):158-65.

93. Spessato BC, Gabbard C, Valentini N, Rudisil M. Gender differences in Brazilian children's fundamental movement skill performance. Early Child Dev Care. 2013;183(3):916-23.

94. Barnett LM, Van Beurden E, Morgan PJ, Brooks LO, Beard JR. Does childhood motor skill proficiency predict adolescent fitness? Med Sci Sports Exerc. 2008;40(12):2137-44.

95. Papaioannou A, Bebetsos E, Theodorakis Y, Christodoulidis T, Kouli O. Causal relationships of sport and exercise involvement with goal orientations, perceived competence and intrinsic motivation in physical education: a longitudinal study. J Sports Sci. 2006;24(4):367-82. 
96. Harter S. Effectance motivation reconsidered toward a developmental model. Hum Dev. 1978;21(1):34-64.

97. Barnett LM, Morgan PJ, van Beurden E, Beard JR. Perceived sports competence mediates the relationship between childhood motor skill proficiency and adolescent physical activity and fitness: a longitudinal assessment. Int J Behav Nutr Phys. 2008;8:5.

98. Robinson LE. The relationship between perceived physical competence and fundamental motor skills in preschool children. Child Care Health Dev. 2011;37(4):589-96.

99. Liong GHE, Ridgers ND, Barnett LM. Associations between skill perceptions and young children's actual fundamental movement skills. Percept Mot Skill. 2015;120(2):591-603.

100. Harter S. The development of competence motivation in the mastery of cognitive and physical skills: is there still a place for joy? In: Roberts G, Landers D, editors. Psychology of motor behaviour and sport. Illinois: Champaign Human Kinetics; 1980. p. 3-29.

101. Loman DG. Promoting physical activity in teen girls: insight from focus groups. MCN Am J Matern Child Nurs. 2008;33(5):294-9; quiz 300-1.

102. Neumark-Sztainer D, Martin SL, Story M. School-based programs for obesity prevention: what do adolescents recommend? Am J Health Promot. 2000;14(4):232-5, iii.

103. Martinez-Vizcaino V, Sanchez-Lopez M, Notario-Pacheco B, Salcedo-Aguilar F, Solera-Martinez M, Franquelo-Morales P, et al. Gender differences on effectiveness of a school-based physical activity intervention for reducing cardiometabolic risk: a cluster randomized trial. Int $\mathrm{J}$ Behav Nutr Phys Act. 2014;11:154.

104. Ryan RM, Deci EL. Intrinsic and extrinsic motivations: classic definitions and new directions. Contemp Educ Psychol. 2000;25(1):54-67.

105. Deeks JJ, Higgins JPT, Altman DG. Analysing data and undertaking meta-analyses. In: Higgins PTJ, Green S, editors. Cochrane handbook for systematic reviews of interventions. London: Wiley; 2008. p. 243-96.

106. Guyatt GH, Oxman AD, Montori V, Vist G, Kunz R, Brozek J, et al. GRADE guidelines: 5. Rating the quality of evidencepublication bias. J Clin Epidemiol. 2011;64(12):1277-82.

107. Egger M, Davey Smith G, Schneider M, Minder C. Bias in meta-analysis detected by a simple, graphical test. BMJ. 1997;315(7109):629-34.

108. Puhan MA, Soesilo I, Guyatt GH, Schunemann HJ. Combining scores from different patient reported outcome measures in meta-analyses: when is it justified? Health Qual Life Outcomes. 2006;4(1):94-101.

109. Leonard HC, Hill EL. The impact of motor development on typical and atypical social cognition and language: a systematic review. Child Adolesc Ment Health. 2014;19:163-70.

110. Diamond A. Close interrelation of motor development and cognitive development and of the cerebellum and prefrontal cortex. Child Dev. 2000;71(1):44-56.

111. Roebers CM, Kauer M. Motor and cognitive control in a normative sample of 7-year-olds. Dev Sci. 2009;12(1):175-81.

112. Smith LB. Cognition as a dynamic system: principles from embodiment. Dev Rev. 2005;25(3-4):278-98.
113. Leonard HC. The impact of poor motor skills on perceptual, social and cognitive development: the case of developmental coordination disorder. Front Psychol. 2016;7:311-4.

114. Smith LB, Thelen E. Development as a dynamic system. Trends Cogn Sci. 2003;7(8):343-8.

115. Ackerman PL. Determinants of individual-differences during skill acquisition-cognitive-abilities and information-processing. J Exp Psychol Gen. 1988;117(3):288-318.

116. Veldman SL, Palmer KK, Okely AD, Robinson LE. Promoting ball skills in preschool-age girls. J Sci Med Sport. 2016. doi:10. 1016/j.jsams.2016.04.009.

117. Barnett LM, Morgan PJ, Van Beurden E, Ball K, Lubans DR. A reverse pathway? Actual and perceived skill proficiency and physical activity. Med Sci Sports Exerc. 2011;43(5):898-904.

118. Hardy LL, Reinten-Reynolds T, Espinel P, Zask A, Okely AD. Prevalence and correlates of low fundamental movement skill competency in children. Pediatrics. 2012;130(2):e390-8.

119. Zachopoulou E, Tsangardidou N, Pickup I, Liukkonen J, Grammatikopoulos V. 'Early Steps'. Promoting healthy lifestyle and social interaction through physical education activities during preschool years. Thessaloniki: Xristodoulidi Publications; 2007.

120. Ames C. Achievement goals, motivational climate, and motivational processes. In: Roberts GC, editor. Motivation in sports and exercise. Champaign: Human Kinetics Publishers; 1992. p. 161-76.

121. Meyer CS. Minds-in-motion: the maze handbook. Louisville: Minds-in-Motion Inc., Press; 2012.

122. Numminen P. APM inventory: manual and test booklet for assessing pre-school children's perceptual and basic motor skills. Jyväskylä: Likes-tutkimuskeskus; 1995.

123. Numminen P. The role of imagery in physical education. Jyväskylä: University of Jyväskylä; 1991.

124. Bruininks RH, Bruininks BD. Bruininks-Oseretsky test of motor proficiency. 2nd ed. Minneapolis: Pearson; 2005.

125. Piek JP, Hands B, Licari MK. Assessment of motor functioning in the preschool period. Neuropsychol Rev. 2012;22(4):402-13.

126. Fisher A, Reilly JJ, Kelly LA, Montgomery C, Williamson A, Paton JY, et al. Fundamental movement skills and habitual physical activity in young children. Med Sci Sports Exerc. 2005;37(4):684-8.

127. Henderson SE, Sugden DA, Barnett AL. Movement assessment battery for children [examiner's manual]. 2nd ed. London: Pearson Assessment; 2007.

128. Krombholz H. Testbatterie zur Erfassung motorischer Leistungen im Vorschulalter MoTB 3-7.Beschreibung, Gütekriterien, Normwerte und ausgewählte Ergebnisse. Saarbrücken: Universitäts- und Landesbibliothek; 2011.

129. Zimmer R, Volkamer M. Motoriktest für vier- bis sechsjährige Kinder (MOT 4-6). 2nd ed. Weinheim: Beltz Test; 1987.

130. Hardin BJ, Peisner-Feinberg ES. The learning accomplishment profile-examiner's manual and technical report. 3rd ed. Lewisville: Kaplan Early Learning Company; 2005.

131. Kakebeeke TH, Locatelli I, Rousson V, Caflisch J, Jenni OG. Improvement in gross motor performance between 3 and 5 years of age. Percept Mot Skills. 2012;114(3):795-806.

132. Folio MR, Fewell RR. Peabody developmental motor scales. 2nd ed. Austin: Pro-Ed; 2000. 